\title{
Impact of mixing state and hygroscopicity on CCN activity of biomass burning aerosol in Amazonia
}

\author{
Madeleine Sánchez Gácita ${ }^{1}$, Karla M. Longo ${ }^{1, a}$, Julliana L. M. Freire ${ }^{1}$, Saulo R. Freitas ${ }^{1, \text { a }}$, and Scot T. Martin ${ }^{2}$ \\ ${ }^{1}$ Center for Weather Forecasting and Climate Research, INPE, Cachoeira Paulista, SP, Brazil \\ ${ }^{2}$ School of Engineering and Applied Science, Harvard University, Cambridge, MA, USA \\ ${ }^{a}$ now at: Universities Space Research Association/Goddard Earth Sciences Technology and Research (USRA/GESTAR) at \\ Global Modeling and Assimilation Office, NASA Goddard Space Flight Center, Greenbelt, MD, USA \\ Correspondence to: Madeleine Sánchez Gácita (madeleine.sanchez@cptec.inpe.br)
}

Received: 22 March 2016 - Discussion started: 18 April 2016

Revised: 15 January 2017 - Accepted: 16 January 2017 - Published: 15 February 2017

\begin{abstract}
Smoke aerosols prevail throughout Amazonia because of widespread biomass burning during the dry season, and external mixing, low variability in the particle size distribution and low particle hygroscopicity are typical. There can be profound effects on cloud properties. This study uses an adiabatic cloud model to simulate the activation of smoke particles as cloud condensation nuclei (CCN) for three hypothetical case studies, chosen as to resemble biomass burning aerosol observations in Amazonia. The relative importance of variability in hygroscopicity, mixing state, and activation kinetics for the activated fraction and maximum supersaturation is assessed. For a population with $\kappa_{\mathrm{p}}=0.04$, an overestimation of the cloud droplet number concentration $N_{\mathrm{d}}$ for the three selected case studies between $22.4 \pm 1.4$ and $54.3 \pm 3.7 \%$ was obtained when assuming a hygroscopicity parameter $\kappa_{\mathrm{p}}=0.20$. Assuming internal mixing of the aerosol population led to overestimations of up to $20 \%$ of $N_{\mathrm{d}}$ when a group of particles with medium hygroscopicity was present in the externally mixed population cases. However, the overestimations were below $10 \%$ for external mixtures between very low and low-hygroscopicity particles, as seems to be the case for Amazon smoke particles. Kinetic limitations were significant for medium- and highhygroscopicity particles, and much lower for very low and low-hygroscopicity particles. When particles were assumed to be at equilibrium and to respond instantly to changes in the air parcel supersaturation, the overestimation of the droplet concentration was up to $\sim 100 \%$ in internally mixed populations, and up to $\sim 250 \%$ in externally mixed ones, being larger for the higher values of hygroscopicity. In addi-
\end{abstract}

tion, a perceptible delay between the times when maximum supersaturation and maximum aerosol activated fraction are reached was noticed and, for aerosol populations with effective hygroscopicity $\kappa_{\mathrm{p}_{\mathrm{eff}}}$ higher than a certain threshold value, the delay in particle activation was such that no particles were activated at the time of maximum supersaturation. Considering internally mixed populations, for an updraft velocity $W=0.5 \mathrm{~ms}^{-1}$ this threshold of no activation varied between $\kappa_{\mathrm{p}_{\text {eff }}}=0.35$ and $\kappa_{\mathrm{p}_{\text {eff }}}=0.5$ for the different case studies. However, for low hygroscopicity, kinetic limitations played a weaker role for $\mathrm{CCN}$ activation of particles, even when taking into account the large aerosol mass and number concentrations. For the very low range of hygroscopicities, the overestimation of the droplet concentration due to the equilibrium assumption was lowest and the delay between the times when maximum supersaturation and maximum activated fraction were reached was greatly reduced or no longer observed (depending on the case study). These findings on uncertainties and sensitivities provide guidance on appropriate simplifications that can be used for modeling of smoke aerosols within general circulation models. The use of medium values of hygroscopicity representative of smoke aerosols for other biomass burning regions on Earth can lead to significant errors compared to the use of low hygroscopicity for Amazonia (between 0.05 and 0.13 , according to available observations). Also in this region, consideration of the biomass burning population as internally mixed will lead to small errors in the droplet concentration, while significantly increasing the computational burden. Regardless of the large 
smoke aerosol loads in the region during the dry season, kinetic limitations are expected to be low.

\section{Introduction}

Aerosol-cloud interactions are a major source of uncertainties in the quantification of climate forcing of aerosols (Bauer and Menon, 2012; IPCC, 2013). The wet size of an aerosol particle when at equilibrium with the environment is governed by Köhler theory (Köhler, 1936) and depends on particle size and composition. In the atmosphere, activation of cloud condensation nuclei $(\mathrm{CCN})$ is a competition between aerosol particles for water vapor, influenced by dynamical processes and the kinetics of particle growth and dependent on the updraft velocities, aerosol number concentrations and differences in size and composition of aerosol particles (McFiggans et al., 2006). Although our understanding of the processes involved in aerosol activation has increased considerably in recent years (Farmer et al., 2015), the inclusion of all the detailed information that might be available about aerosol populations into global and regional circulation models is often impractical. Thus, assessments of the uncertainties derived from simplifications assumed are relevant and potentially contribute to the discussion on the level of sophistication required by general circulation models (GCMs) with the aim of decreasing the uncertainties.

A large quantity of aerosol particles is generated globally by open biomass burning (Granier et al., 2011; Lamarque et al., 2010; van der Werf et al., 2010), and the impacts of smoke aerosols in climate, air quality and geochemistry have being addressed in several studies (Andreae, 1991; Crutzen and Andreae, 1990; Jacobson, 2004; Langmann et al., 2009; Tosca et al., 2013, and references therein). Vegetation fires plumes can be entrained into upper levels of the troposphere and undergo long-range transport before being removed from the atmosphere if conditions are favorable, e.g., when convection activity is high (Andreae, 1991; Andreae et al., 2001; Freitas et al., 2005; Fromm and Servranckx, 2003). During the dry season in South America, observation and numerical model results agree in that biomass burning aerosol originated from extensive fires typically detected over the Amazon and central Brazil regions, represents a significant fraction of the aerosol burden in southern and southeastern parts of Brazil, in Uruguay and in northern Argentina (Camponogara et al., 2014; Freitas et al., 2005; Longo et al., 2010; Ramanathan, 2001; Rosário et al., 2013; Wu et al., 2011).

Even though a large fraction of biomass burning aerosols has low to moderate hygroscopicity (Carrico et al., 2010; Dusek et al., 2011; Engelhart et al., 2012; Petters et al., 2009; Rissler et al., 2004, 2006), biomass burning particles can act as CCN under sufficiently high atmospheric water vapor supersaturations (Mircea et al., 2005; Rose et al., 2010; Vestin et al., 2007). Therefore, $\mathrm{CCN}$ activation properties of pyro- genic particles are likely to be relevant for the aerosol climate forcing.

Some external mixing in terms of hygroscopicity seems to be rather common in aerosol populations, particularly over continents (Kandler and Schütz, 2007; Swietlicki et al., 2008). However, average hygroscopicity parameters have been estimated from both observational and modeled data assuming internal mixing for aerosols from the same emission source (e.g., biomass burning), or even within the same geographical region (Gunthe et al., 2009; Pringle et al., 2010). Sensitivity of CCN activation to hygroscopic mixing state under equilibrium conditions is also significant, and the assumption of total internal mixing could result in an overestimation of the $\mathrm{CCN}$ population that can range from 10 to $100 \%$ (Cubison et al., 2008; Ervens et al., 2010; Padró et al., 2012; Wex et al., 2010). The impact of mixing state under dynamic conditions has, however, been less studied, and some evidence suggests that conclusions from equilibrium conditions might not be directly extrapolated to $\mathrm{CCN}$ activation during cloud formation (Cubison et al., 2008; Ervens et al., 2010).

The aerosol particle's composition is known to influence the particle water uptake and $\mathrm{CCN}$ activation (Almeida et al., 2014; Mircea et al., 2005; Roberts et al., 2003). Although the effects of composition on the cloud droplet number concentrations are typically secondary when compared to those of population number concentration and size distribution (Dusek et al., 2006; Feingold, 2003; Hudson, 2007; McFiggans et al., 2006; Reutter et al., 2009), the extent to which these effects can be safely neglected in GCMs is also yet to be established. Droplet number concentrations were shown to be more sensitive to the presence of organic content than to the updraft velocity in some situations (Rissman et al., 2004). On conditions typical of pyrocumulus (number concentrations up to $10^{5} \mathrm{~cm}^{-3}$ and updraft velocities up to $20 \mathrm{~m} \mathrm{~s}^{-1}$ ), Reutter et al. (2009) found that cloud droplet number concentration was sensitive to compositional effects (hygroscopicity). For three different ratios of the aerosol number concentrations to the updraft velocity, and for a fixed aerosol size distribution, the authors found that the sensitivity to hygroscopicity was low for medium to high hygroscopic values, but moderate for very low and low hygroscopicity values (Reutter et al., 2009). Still, sensitivities to hygroscopicity are likely to be tightly related to the position of the dry critical size of the smallest activated particle within the overall size distribution of the aerosol population, and significant sensitivities have been obtained for the population of small aerosol particles with medium and high hygroscopicity (Ward et al., 2010).

Aerosol particles with critical supersaturations smaller than the maximum supersaturation reached within the cloud can nonetheless become interstitial aerosols due to the evaporation and deactivation mechanisms described by Nenes et al. (2001). These kinetic limitations, sometimes neglected in GCMs, are expected to be large when significant aerosol 
loads are present (Nenes et al., 2001). Consequently, parameterizations that assume equilibrium conditions overestimate $\mathrm{CCN}$ when kinetic limitations are important (Nenes et al., 2001; Phinney et al., 2003). However, little is known about how kinetic limitations are related with the particle hygroscopicity, although a relation between the timescale of the components solubility and activation has been reported (Chuang, 2006).

On the other hand, several observational biomass burning studies conducted in the Amazon region reported rather similar number size distributions for biomass burning aerosols within the boundary layer (Andreae et al., 2004; Artaxo et al., 2013; Brito et al., 2014; Reid et al., 1998; Rissler et al., 2004, 2006). In terms of hygroscopicity, these smoke particles have been found to be externally mixed (Rissler et al., 2004, 2006). Their population effective hygroscopicity parameter, converted from the original data using expressions suggested by Gunthe et al. (2009), ranged between 0.05 and 0.13 (Rissler et al., 2004, 2006); these compare well with observed values for biomass burning aerosols but are rather on the lower side of the range of values reported elsewhere. Reported values of the hygroscopicity parameter for freshly emitted smoke particles in biomass burning laboratory experiments reached values up to 0.6 , although a significant number of data indicated values between 0.02 and 0.2 , with wood species and smoldering fires producing the less hygroscopic particles (Carrico et al., 2010; Dusek et al., 2011; Engelhart et al., 2012; Petters et al., 2009). An average hygroscopicity parameter of 0.21 was obtained for a 4-day biomass burning episode near Guangzhou, China, using airborne data (Rose et al., 2010). The hygroscopicity parameter obtained from $\mathrm{CCN}$ airborne measurements for boreal fires biomass burning aerosols in Canada was 0.18 for both recently emitted and aged aerosols, while the values estimated assuming an average chemical composition were, on average, 0.11 for fresh aerosol particles and 0.24 for aged ones, both within the level of variability in the value estimated from $\mathrm{CCN}$ measurements (Lathem et al., 2013). A recent study of the hygroscopicity of recently emitted and aged smoke particles reported ranging between 0.05 and 0.1 for the same parameter in Thailand (Hsiao et al., 2016).

In the present study, we used an adiabatic cloud model to simulate the CCN activation of biomass burning particles, aiming to contribute to the understanding of the possible impact of different hygroscopicity values, mixing state and kinetic limitations in the CCN activated fraction. The modeling approach followed is described in Sect. 2. According to the available observations of biomass burning aerosols in the Amazon region, three typical situations in terms of size distributions and other aerosol parameters were considered in the definition of the case studies and other simulation parameters, as described in Sect. 3. Finally, the results from the cloud parcel model and our conclusions are discussed in Sects. 4 and 5 .

\section{Modeling approach}

\subsection{Cloud parcel model}

A model of an air parcel assumed to ascend adiabatically at a prescribed updraft velocity and without entrainment to supersaturation conditions was used to study the activation of aerosol particles in the first stages of cloud development. The air parcel model used in this work is based on the model described by Pruppacher and Klett (1997), with the supersaturation and liquid water mixing ratio tendencies estimated as in Seinfeld and Pandis (2006) and the equilibrium supersaturation calculated as proposed by Petters and Kreidenweis using the hygroscopicity parameter $\kappa_{\mathrm{p}}$ (Petters and Kreidenweis, 2007). The pressure is estimated assuming the environment is in hydrostatic equilibrium, and the temperature and water vapor mixing ratio are estimated from the moisture and heat conservation, respectively (Pruppacher and Klett, 1997). The surface tension dependence on temperature is relevant to CCN activation (Christensen and Petters, 2012), and it is calculated as $\sigma_{w / a}=7.61 \times 10^{-2}-1.55 \times 10^{-4}(T-273.15)$ (Seinfeld and Pandis, 2006) .

The aerosol dry size distribution for each hygroscopic group is discretized into $(n)$ bins with a fixed volume ratio for all bins. Particles that belong to bin size $(i)$ and hygroscopic group (hg) are assumed to grow equally when exposed to the same conditions. Coagulation and coalescence processes are not considered, so the number of particles in each bin remains constant while their wet sizes change over time (fullmoving size structure) (Jacobson, 2005). In this work, the particle's critical diameter is determined for each bin size and hygroscopic group as the value that maximized the particle's equilibrium supersaturation. Aerosol particles with wet size larger than their critical size are considered activated. Particles larger than strictly activated particles are considered cloud droplets as well because they have wet sizes larger than that of cloud droplets and can condense significant quantities of water vapor on their surfaces (Nenes et al., 2001). The total cloud droplet number concentration estimated without assuming equilibrium conditions, $N_{\mathrm{d} \text {,neq, }}$, is the sum of strictly activated particles and those with wet sizes larger than activated particles. To abbreviate the notation, hereafter $N_{\mathrm{d}}$ will refer to $N_{\mathrm{d} \text {,neq }}$ at the end of the simulation, unless otherwise stated.

Some parameterizations of CCN activation neglect kinetic limitations (Ghan et al., 2011). A notable example of one such parameterization is the one proposed by Abdul-Razzak and Ghan $(2000,2002)$, widely used in GCMs (Ban-weiss et al., 2014; Bauer et al., 2010; He et al., 2015; Makkonen et al., 2014; Pierce et al., 2015, and references therein). In this parameterization it is assumed that particles are in equilibrium with the environment until the maximum supersaturation is reached, and that all particles with critical supersaturation less than or equal to the air parcel maximum supersaturation are consider activated. 
If particles are presumed to respond instantly to changes in the air parcel supersaturation, particles with critical supersaturation lower than a given supersaturation $s$ will also have dry sizes larger than a dry particle cut diameter $d_{\text {dry,c }}$ (details in Appendix B). The cloud droplet concentration estimated thus, here denoted $N_{\mathrm{d} \text {,eq }}$, effectively represent the maximum cloud droplet concentration attainable at supersaturation $s$. If evaporation and deactivation mechanisms of kinetic limitations (Nenes et al., 2001) are significant, the calculation of the cloud droplet spectra from the maximum supersaturation assuming equilibrium will lead to an overestimation of the cloud droplet number concentration. In an intermediate approach, particles can be considered cloud droplets if their wet diameters are larger than the approximate cut wet diameter $d_{\mathrm{c}}$ that corresponds to $d_{\mathrm{dry}, \mathrm{c}}$ in equilibrium conditions (Appendix B). This approximate estimation, denoted $N_{\mathrm{d} \text {,neq }} \mathrm{q}_{\text {simp }}$, considers kinetic effects to some extent since the wet sizes of particles that are compared to $d_{\mathrm{c}}$ are calculated explicitly in the cloud model. In order to measure the impact of kinetic limitations in the simulations, estimations by the three aforementioned methods are presented. In addition, the ratio between the equilibrium droplet concentration corresponding to the maximum supersaturation and the droplet concentration, $\max \left(N_{\mathrm{d} \text {,eq }}\right) / N_{\mathrm{d} \text {,neq }}$, was estimated at the time of maximum supersaturation and at the end of the simulation.

The cloud parcel model described was fully implemented in Mathematica ${ }^{\circledR} 10.0$ (Wolfram Research, 2014). Equations for the size of particles in each bin, supersaturation, liquid water mixing ratio, water vapor mixing ratio, air pressure and temperature form a closed system of $n+5$ nonlinear ordinary differential equations (ODEs) in which derivatives depend not only on the set of variables but also on their derivatives as well. The ODE system was solved using the IDA method from SUNDIAL package (SUite of Nonlinear and DIfferential/ALgebraic equation Solvers) (Hindmarsh, 2000; Hindmarsh and Taylor, 1999), as implemented in the function NDSOLVE of Mathematica. Symbols frequently mentioned in this section and through the text are summarized in Appendix A.

\subsubsection{Sensitivity of CCN to a parameter}

Sensitivities $S\left(X_{i}\right)$ in the context of CCN activation were first introduced by Feingold (2003) as the slope in the linear regression to the logarithms of cloud-top effective droplet radius $r_{\text {eff }}$ as a function of the logarithms of the parameter $X_{i}$, i.e., $S_{X_{i}}=\partial \ln r_{\text {eff }} / \partial \ln X_{i}$. Later on, McFiggans et al. (2006) proposed sensitivities of the droplet number concentration $N_{\mathrm{d}}$ to a parameter $X_{i}$ :

$S_{X_{i}}=\frac{\partial \ln \left(N_{\mathrm{d}}\right)}{\partial \ln \left(X_{i}\right)}$.

According to Eq. (1), $N_{\mathrm{d}} \propto X_{i}{ }^{S_{X_{i}}}$ and a sensitivity closer to zero indicate a smaller increase in $N_{\mathrm{d}}$ as parameter $X_{i}$ increases. Sensitivities were calculated from linear regressions
Table 1. Parameters for the Aitken and accumulation lognormal number size distribution for the defined case studies.

\begin{tabular}{lrrr}
\hline & $N_{m}\left(\mathrm{~cm}^{-3}\right)$ & $d_{m}(\mathrm{~nm})$ & $\sigma_{m}$ \\
\hline Case $\mathrm{MP}_{5,1}$ & & & \\
\hline Aitken & 5000 & 95 & 1.60 \\
Accumulation & 1000 & 180 & 1.50 \\
\hline Case $\mathrm{MP}_{1,5}$ & & & \\
\hline Aitken & 1000 & 95 & 1.60 \\
Accumulation & 5000 & 180 & 1.50 \\
\hline Case $\mathrm{HP}_{5,5}$ & & & \\
\hline Aitken & 5000 & 95 & 1.60 \\
Accumulation & 5000 & 180 & 1.50 \\
\hline
\end{tabular}

in $\ln N_{\mathrm{d}}$ vs. $\ln X_{i}$ curves as averages (slope of the linear fit) and locally (derivatives of the curves in the $\ln -\ln$ space).

\section{Definition of case studies and simulation parameters}

In this work, three hypothetical different size distributions were defined as case studies for the cloud model simulations (Table 1). The corresponding number size distributions are depicted in Fig. 1. The parameters of the selected size distributions were chosen as to resemble biomass burning aerosol observations in Amazonia (resumed in Table S1 of the Supplement) while trying to minimize the impact of particle size and standard deviation. The first case is a moderately polluted case with $5000 \mathrm{~cm}^{-3}$ particles in the Aitken mode, and $1000 \mathrm{~cm}^{-3}$ in the accumulation modes, respectively $\left(\mathrm{MP}_{5,1}\right)$ (Fig. 1a). Case $\mathrm{MP}_{5,1}$ is similar to the observed distribution during the SAMBBA experiment (South American Biomass Burning Analysis, 2012) (Brito et al., 2014). The second is a case study with the same number concentration than $\mathrm{MP}_{5,1}$, but with higher number of particles in the accumulation mode, with 1000 and $5000 \mathrm{~cm}^{-3}$ in the accumulation and Aitken modes, respectively $\left(\mathrm{MP}_{1,5}\right)$ (Fig. $1 \mathrm{~b}$ ). The size distribution of case $\mathrm{MP}_{1,5}$ is comparable to the observed during LBA-SMOCC (Large-Scale Biosphere Atmosphere Experiment in Amazonia - Smoke Aerosols, Clouds, Rainfall, and Climate, 2002) dry-to-wet transition period. There was also a predominance of particles in the accumulation mode during the biomass burning episodes of LBA-CLAIRE (Cooperative LBA Airborne Regional Experiment, 2001) (Rissler et al., 2004), although particle number concentrations were lower for these periods. Finally, the last case is a highly polluted case $\left(\mathrm{HP}_{5,5}\right)$ (Fig. 1c) with $5000 \mathrm{~cm}^{-3}$ in both modes, resembling the observed distribution during the SMOCC dry period (Rissler et al., 2006), minus the nucleation mode. Particles in the nucleation mode are not expected to impact significantly the $\mathrm{CCN}$ behavior of the aerosol population and were disregarded. 

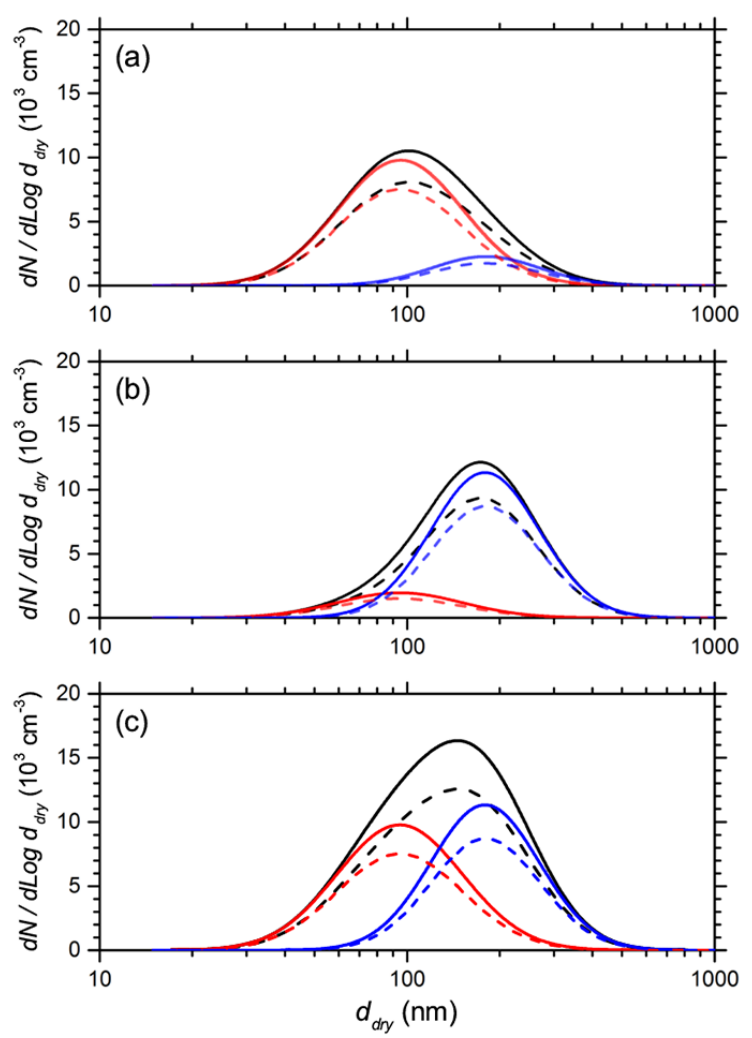

Figure 1. Schematic number size distributions for $\mathrm{MP}_{5,1}$ (a), $\mathrm{MP}_{1,5}$ (b) and $\mathrm{HP}_{5,5}$ (c) case studies. Total population (black, solid), Aitken (red, solid) and accumulation (blue, solid) modes are indicated. Particles in hygroscopic group $\kappa_{\mathrm{p}}=0.04$ (dashed line, all colors) are also shown for a population average $\kappa_{\mathrm{p}_{\text {eff }}}=0.10$.

In both CLAIRE and SMOCC experiments, smoke particles were found to be externally mixed in terms of hygroscopicity (Rissler et al., 2004, 2006). The less hygroscopic group presented very low hygroscopicity $\kappa_{\mathrm{p}}$ values, between 0.032 and 0.068 , while the $\kappa_{\mathrm{p}}$ values for the more hygroscopic group were low, ranging between 0.110 and 0.172 (Rissler et al., 2004, 2006) (Table S2 of Supplement). Here, the following classification by Gunthe et al. (2009) was considered: very low hygroscopicity $\left(\mathrm{VLH}, \kappa_{\mathrm{p}}<0.1\right)$, low hygroscopicity $\left(\mathrm{LH}, 0.1 \leq \kappa_{\mathrm{p}}<0.2\right)$, medium hygroscopicity $\left(\mathrm{MH}, 0.2 \leq \kappa_{\mathrm{p}}<0.4\right)$ and high hygroscopicity $\left(\mathrm{HH}, \kappa_{\mathrm{p}} \geq\right.$ 0.4). Neither set of observations included smoke particles with $\kappa_{\mathrm{p}}>0.2$. The hygroscopic group number fractions varied, with very low hygroscopicity particles accounting for $20 \%$ of the total number concentration (Rissler et al., 2004), or up to $85 \%$ (Rissler et al., 2006) (Table S2). As a result, the population effective hygroscopicity parameter $\kappa_{\mathrm{p}_{\text {eff }}}$ ranged between 0.05 and 0.13 .

To assess the role of aerosol mixing state outside equilibrium conditions, cloud model simulations were conducted for populations both externally and internally mixed. The variability in the population effective $\kappa_{\mathrm{p}_{\text {eff }}}$ was simulated as-
Table 2. Number fractions for the hygroscopic groups in the externally mixed populations $\mathrm{Ext}_{1}$ and $\mathrm{Ext}_{2}$.

\begin{tabular}{rrr|rr}
\hline & \multicolumn{2}{c|}{ Ext $_{1}$} & \multicolumn{2}{|c}{$\mathrm{Ext}_{2}$} \\
\cline { 2 - 5 }$\kappa_{\mathrm{p}_{\text {eff }}=}=$ & & & & \\
$\sum \kappa_{\mathrm{phg}} f_{\mathrm{hg}}$ & $f_{\kappa_{\mathrm{p}}=0.04}$ & $f_{\kappa_{\mathrm{p}}=0.16}$ & $f_{\kappa_{\mathrm{p}}=0.04}$ & $f_{\kappa_{\mathrm{p}}=0.30}$ \\
\hline 0.04 & 1.00 & 0.00 & 1.00 & 0.00 \\
0.06 & 0.83 & 0.17 & 0.92 & 0.08 \\
0.08 & 0.67 & 0.33 & 0.85 & 0.15 \\
0.10 & 0.50 & 0.50 & 0.77 & 0.23 \\
0.12 & 0.33 & 0.67 & 0.69 & 0.31 \\
0.14 & 0.17 & 0.83 & 0.62 & 0.38 \\
0.16 & 0.00 & 1.00 & 0.54 & 0.46 \\
0.18 & - & - & 0.46 & 0.54 \\
0.20 & - & - & 0.38 & 0.62 \\
0.25 & - & - & 0.19 & 0.81 \\
0.30 & - & - & 0.00 & 1.00 \\
\hline
\end{tabular}

suming that the population is composed by two populations externally mixed in terms of hygroscopicity, having $\kappa_{\mathrm{p}}=$ 0.04 and $\kappa_{\mathrm{p}}=0.16$, respectively, with a resultant population effective hygroscopicity estimated as $\kappa_{\mathrm{p}_{\text {eff }}}=\sum \kappa_{\mathrm{phg}} f_{\mathrm{hg}}$ (Gunthe et al., 2009) that varies according to the number fraction $f_{\text {hg }}$ of each hygroscopic group, hg (Table 2). This case is denoted Ext 1 . A second possibility, denoted Ext 2 , was considered to account for more hygroscopic biomass burning aerosols observed for other biomass/regions. In this second case, the $\kappa_{\mathrm{p}}$ of the more hygroscopic group is increased from $\kappa_{\mathrm{p}}=0.16$ to a medium hygroscopicity value, $\kappa_{\mathrm{p}}=0.30$, with a resultant population effective hygroscopicity also varying according to the number fraction of each hygroscopic group (Table 2). Finally, the internally mixed population was denoted Int. Results obtained for two hygroscopic groups of particles externally mixed are compared with results obtained if the population is assumed to be internally mixed. The minimum/maximum $\kappa_{\mathrm{p}_{\text {eff }}}$ in both sets of externally mixed populations is reached for the extreme case when only one group is present (therefore reducing to the internally mixed case) and is equal to the hygroscopicity parameter of particles in this group.

The effective $\kappa_{\mathrm{p}_{\text {eff }}}$ and the corresponding fractions of each group for both situations and different fractions of the hygroscopic groups are presented in Table 2. The schematic size distribution of the aerosol total population and that of the hygroscopic group with $\kappa_{\mathrm{p}}=0.04$ are indicated in Fig. 1 for the three case studies, for a $\kappa_{\mathrm{p}_{\text {eff }}}=0.10$ and Ext 2 external mixing state. The aerosol composition was considered to be independent of particle size, assuming that the slight tendency of higher hygroscopicity of larger particles (Table S2) was typically not large enough to impact significantly the CCN behavior of the population. Simulations were conducted for the internally mixed population (Int) with hygroscopicities that ranged from $\kappa_{\mathrm{p}}=0.02$ to $\kappa_{\mathrm{p}}=0.60$, for the defined $\mathrm{MP}_{5,1}$, 
$\mathrm{MP}_{1,5}$ and $\mathrm{HP}_{5,5}$ cases, in order to analyze the effect of hygroscopicity. Simulations conducted for the externally mixed population $\left(\mathrm{Ext}_{1}\right.$ and $\left.\mathrm{Ext}_{2}\right)$ ranged between the minimum and maximum $\kappa_{\mathrm{p}_{\text {eff }}}(0.04$ to 0.16 and 0.04 to 0.30 , respectively).

Updraft velocities between 0.1 and $10 \mathrm{~m} \mathrm{~s}^{-1}$ were considered. Higher number concentrations than considered here can be found in pyrocumulus, but it is probably safe to assume that their impact on the hydrological cycle and aerosol indirect effect on a regional scale is secondary when compared with that of the regional haze, so these extreme cases of polluted conditions were not covered in our study. According to the regimes proposed by Reutter et al. (2009), our study focused largely on the aerosol-limited and aerosol- and updraft-sensitive regimes, with particle number concentrations that characterize polluted conditions like those found in the regional haze. For $\mathrm{MP}_{5,1}$ and $\mathrm{MP}_{1,5}$ cases, the updraftlimited case is given approximately by $W \leq 1 \mathrm{~m} \mathrm{~s}^{-1}$, but the aerosol-limited is given by $W \geq 6 \mathrm{~ms}^{-1}$. For the $\mathrm{HP}_{5,5}$ case, the approximate limit of the updraft-limited case is given by $W \leq 1 \mathrm{~m} \mathrm{~s}^{-1}$, and the aerosol-limited by $W \geq 10 \mathrm{~m} \mathrm{~s}^{-1}$ (not considered in our simulations).

Cloud-base initial conditions for the simulations were temperature of $293 \mathrm{~K}$, atmospheric pressure of $900 \mathrm{hPa}$ and relative humidity of $98 \%$. Sensitivity tests indicated only a weak dependence (absolute differences between maximum supersaturations obtained initializing at 80 and at $99 \%$ below $0.03 \%$ ) of maximum supersaturations with the initial relative humidity for the highest updraft values, and a negligible effect in the activated fraction (see Fig. S1 of the Supplement). To avoid unrealistic physical parameters, the final time of simulation was defined somewhat arbitrarily as the time required for the parcel to ascend $500 \mathrm{~m}$ at the considered updraft velocity. The parameters for the simulations are summarized in Table 3 . The distribution was discretized into 1000 bins ranged from 15 to $10^{4} \mathrm{~nm}$, leading to a relative error of less than $0.003 \%$ with respect to the lognormal distribution for all the cases considered in this study. To exclude particles that are not large enough to activate, only particles larger than $30 \mathrm{~nm}\left(N_{\mathrm{a}, 30}\right)$ were considered as aerosol number concentrations in the calculation of $N_{\mathrm{d}} / N_{\mathrm{a}}$ fractions. For all the cases considered, the cloud nuclei larger than $30 \mathrm{~nm}$ fraction included almost all particles, with the lowest fraction $N_{\mathrm{a}, \text { total }} / N_{\mathrm{a}, 30}=0.994$ obtained for case $\mathrm{MP}_{5,1}$.

\section{Results and discussion}

Maximum values of supersaturation and $\mathrm{CCN}$ activated fraction, as a function of hygroscopicity, updraft velocity and mixing state, are presented in Fig. 2 for the various proposed case studies and mixing states. Due to the high particle number concentrations that characterize polluted conditions in the three case studies, maximum supersaturations reached in the simulations were typically low and, except for the highest updraft velocities and for very low hygroscopicity values
Table 3. Parameters for the simulations.

\begin{tabular}{ll}
\hline Parameter & Value/range \\
\hline Updraft velocity & $0.1-10 \mathrm{~m} \mathrm{~s}^{-1}$ \\
\hline Hygroscopicity parameter & \\
\hline Int & $0.02-0.60$ \\
Ext $_{1}$ & $0.04-0.16$ \\
Ext $_{2}$ & $0.04-0.30$ \\
\hline Initial conditions & \\
\hline Relative humidity & $98 \%$ \\
Temperature & $293 \mathrm{~K}$ \\
Atmospheric pressure & $900 \mathrm{hPa}$ \\
Air parcel height & $500 \mathrm{~m}$ \\
\hline
\end{tabular}

(VLH, $\kappa_{\mathrm{p}}<0.1$ ), had values below $0.5 \%$ in the $\mathrm{MP}_{5,1}$ case and below $0.4 \%$ in the $\mathrm{MP}_{1,5}$ and $\mathrm{HP}_{5,5}$ cases. The highest values of maximum supersaturation were obtained for the $\mathrm{MP}_{5,1}$ case, with the majority of particles in the Aitken mode. Maximum supersaturations in this case were, on average, $\sim 0.10 \%$ larger (absolute differences) than those obtained for $\mathrm{MP}_{1,5}$ case, and about $0.15 \%$ higher than those obtained for $\mathrm{HP}_{5,5}$ case. Meanwhile, the values of maximum supersaturation reached in the $\mathrm{MP}_{1,5}$ case study were higher than those obtained in the $\mathrm{HP}_{5,5}$ case, but slightly higher, with absolute differences between maximum supersaturation values of up to $0.05 \%$, all else being equal, in spite of the much higher particle number concentrations in the latter case. The case study with the highest $N_{\mathrm{a}}, \mathrm{HP}_{5,5}$, presented the largest cloud droplet number concentrations. However, the largest $N_{\mathrm{d}} / N_{\mathrm{a}}$ fractions were instead reached in the $\mathrm{MP}_{1,5}$ case, all else being equal. The activated fractions for the $\mathrm{HP}_{5,5}$ case were the lowest between all three cases for all values of $\kappa_{\mathrm{p}}$ within the low hygroscopicity $\left(\mathrm{LH}, 0.1 \leq \kappa_{\mathrm{p}}<0.2\right)$ and medium hygroscopicity ( $\left.\mathrm{MH}, 0.2 \leq \kappa_{\mathrm{p}}<0.4\right)$ ranges, while for $\kappa_{\mathrm{p}}$ in the VLH range the lowest $N_{\mathrm{d}} / N_{\mathrm{a}}$ fractions were obtained for the $\mathrm{MP}_{5,1}$ case.

These results for the maximum supersaturations and $N_{\mathrm{d}} / N_{\mathrm{a}}$ fractions are explained by the Köhler theory, which predicts that the Kelvin term typically dominates the growing process for larger particles, while the Raoult term is more relevant for smaller ones. Therefore, particles in the accumulation mode are likely to condense water vapor on their surfaces more readily than the comparatively smaller particles in the Aitken mode, growing larger and impacting the maximum supersaturation reached more than the latter. Moreover, the Raoult term is more significant the smaller the particle; thus, the activation of particles in the Aitken mode is expected to be more altered by hygroscopicity than the activation of particles in the accumulation mode.

Among the variable parameters within the simulations, both maximum supersaturations and $N_{\mathrm{d}} / N_{\mathrm{a}}$ fractions were impacted the most by updraft velocity, for all study cases and 


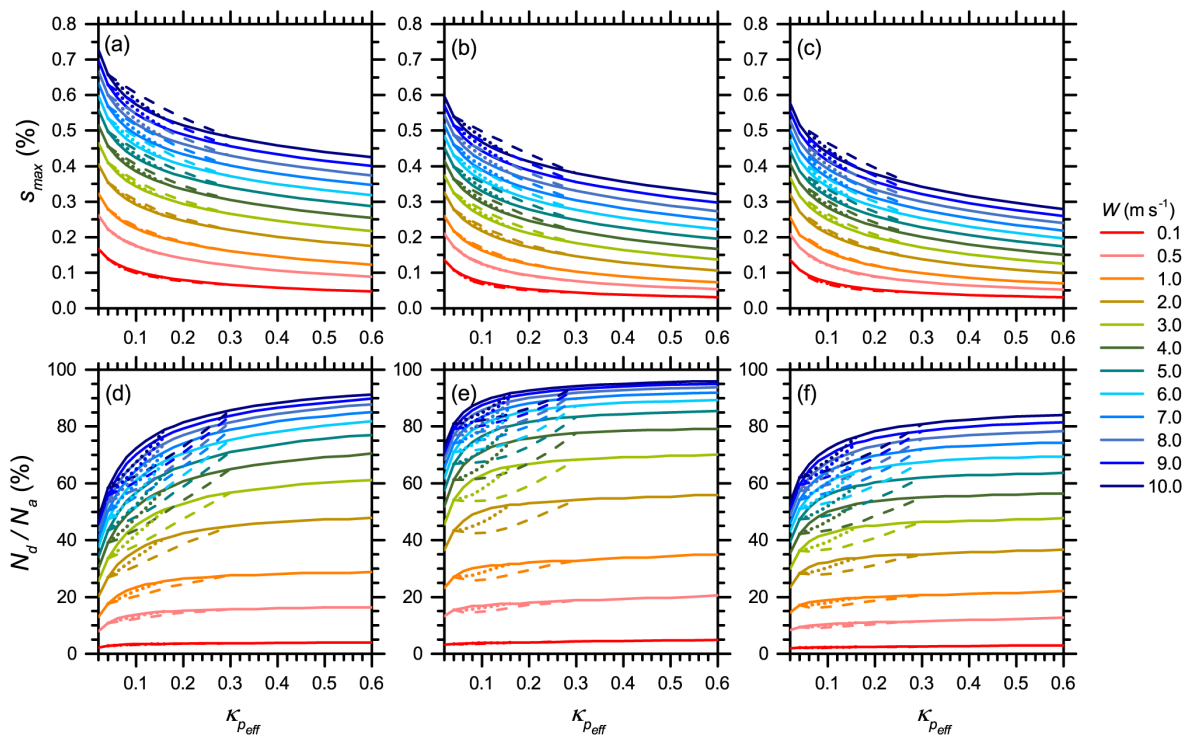

Figure 2. Maximum supersaturation reached (top) and fraction of particles activated (bottom) for the internal mixing (solid line) and external mixing cases Ext 1 (dotted line) and $\mathrm{Ext}_{2}$ (dashed line). Plots on columns (a, d), (b, e) and (c, e) are for $\mathrm{MP}_{5,1}, \mathrm{MP}_{1,5}$ and $\mathrm{HP}_{5,5}$ case studies, respectively. The color scale refers to the updraft velocities from 0.1 to $10 \mathrm{~m} \mathrm{~s}^{-1}$.

mixing states. Mean sensitivities of $N_{\mathrm{d}}$ to $W$ in the $\mathrm{MP}_{5,1}$, $\mathrm{MP}_{1,5}$ and $\mathrm{HP}_{5,5}$ study cases were $0.66,0.65$ and 0.73 , respectively, with very little variability with mixing state, as illustrated in Fig. 3 for $\kappa_{\mathrm{p}_{\text {eff }}}=0.10$. These mean values of $S_{W}$ are higher than previous estimations of 0.18 and 0.47 for clean $\left(<1000 \mathrm{~cm}^{-3}\right)$ and polluted $\left(1000-3000 \mathrm{~cm}^{-3}\right)$ conditions, respectively, by McFiggans et al. (2006). However, an increase in the sensitivity to $W$ with the number concentration is consistent with the behavior expected within the updraft- and aerosol-sensitive regime that is, on average, the predominating regime. The adjusted $R^{2}$ coefficients in the linear fits of the $\ln N_{\mathrm{d}}$ vs. $\ln W$ curves were $\geq 0.90$ for all cases and mixing states. However, the data points departed from the mean slope towards low and high updraft velocities for all case studies and mixing states (Fig. 3, top). Cloud droplet number concentrations were more sensitive (local $S_{W}$ up to 0.9 ) to increases in the updraft velocity for velocities within the updraft-limited regime, while for the aerosollimited regime the sensitivity to $W$ decreased to values between 0.1 and 0.4 (Fig. 3, bottom). This varying sensitivity of $N_{\mathrm{d}}$ to $W$ is in agreement with the changing behavior within each regime of $\mathrm{CCN}$ activation described by Reutter et al. (2009), which varies from a high sensitivity of activation with $W$ in the updraft-limited regime to almost no influence in the aerosol-limited one. The sensitivity of $N_{\mathrm{d}}$ to the aerosol number concentrations and the geometric mean diameter and standard deviation have been discussed elsewhere (McFiggans et al., 2006; Reutter et al., 2009) and was not addressed here.
In contrast with $S_{W}$, the sensitivity to hygroscopicity $S_{\kappa_{\mathrm{p}}}$ changed substantially with mixing state; this will be discussed in Sect. 4.2.

\subsection{Aerosol mixing state}

The aerosol mixing state modified both maximum supersaturations and activated fractions, although to different extents. The values of maximum supersaturation were slightly underestimated for updraft velocities in the aerosol-limited and the aerosol- and updraft-sensitive regimes when internal mixing was assumed (Fig. 2, top). The absolute differences were up to $\sim 0.01$ and $\sim 0.03 \%$ for the externally mixed Ext $t_{1}$ and $\mathrm{Ext}_{2}$ populations, respectively. For updraft velocities within the updraft-limited regime, however, the maximum supersaturation reached were lowest, and the values assuming an internal mixing were almost identical or marginally higher than those reached for externally mixed populations.

On the other hand, the internal mixing hypothesis typically led to overestimations of $N_{\mathrm{d}}$, regardless of the somewhat lower values of maximum supersaturation reached for this mixing case. The effect of hygroscopic mixing state in the CCN activation behavior of aerosols can be illustrated through the consideration of an aerosol population with known size and composition but no information on the mixing state. Particles in the externally mixed population will have either larger or smaller hygroscopicity parameters than that of the internally mixed population average. The more hygroscopic groups in the external mixture will have smaller cut particle diameters and will activate more readily than the internally mixed particles. Consequently, if internal mixing 

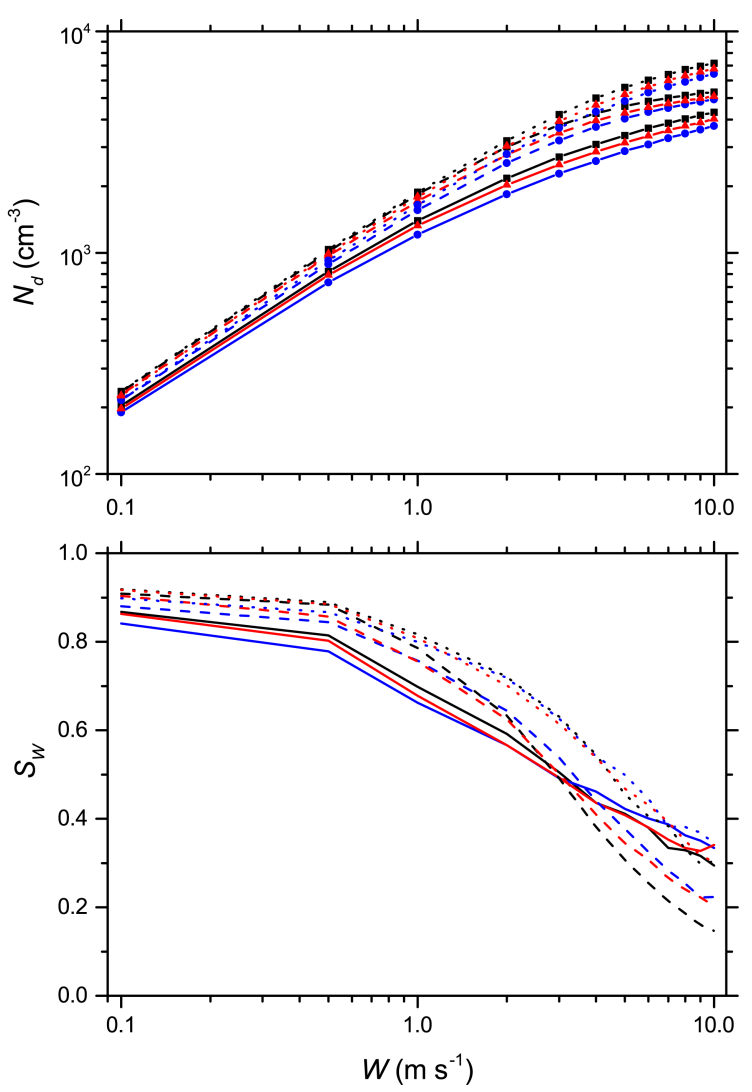

Figure 3. Number of particles activated (top) and sensitivity $S_{W}$ of $N_{\mathrm{d}}$ to the updraft velocity $W$ (bottom) for $\kappa_{\mathrm{p}_{\text {eff }}}=0.10$, obtained for the $\mathrm{MP}_{5,1}$ (solid line), $\mathrm{MP}_{1,5}$ (dashed line) and $\mathrm{HP}_{5,5}$ (dotted line) case studies. Results for internal mixed Int population and externally mixed populations $\mathrm{Ext}_{1}$ and $\mathrm{Ext}_{2}$ are in black, red and blue, respectively.

is presumed, the number of more hygroscopic particles that become cloud droplets would be underestimated.

Although differences in activation for more and less hygroscopic particles due to internal mixing will contribute with opposite signs to the total $N_{\mathrm{d}}$ derived from mixing state, they are unlikely to cancel each other out. In a simulation selected to illustrate the impact of mixing state in $N_{\mathrm{d}}$, an externally mixed population $\left(\mathrm{Ext}_{2}\right)$ has one hygroscopic group with $\kappa_{\mathrm{p}}=0.04$, in the VLH range, present in a fraction $f_{\kappa_{\mathrm{p}}}=0.04=0.77$, and a second hygroscopic group with $\kappa_{\mathrm{p}}=0.30$, within the MH range, with $f_{\kappa_{\mathrm{p}}}=0.30=0.23$. Assuming internal mixing (Int), these two groups resulted in $\kappa_{\mathrm{p}_{\text {eff }}}=0.10$ (Table 2). For this specific case, the schematic size distribution of particles that are activated as $\mathrm{CCN}$ in the $\mathrm{MP}_{5,1}, \mathrm{MP}_{1,5}$ and $\mathrm{HP}_{5,5}$ case studies at a prescribed updraft velocity of $W=5 \mathrm{~m} \mathrm{~s}^{-1}$ are presented for external and internal mixtures in Fig. 4. The values of maximum supersaturations reached were somewhat lower when internal mixing state was assumed, between 2 and $3 \%$ depending on the study case. A fraction of particles in the $\mathrm{MH}$ hygroscopic
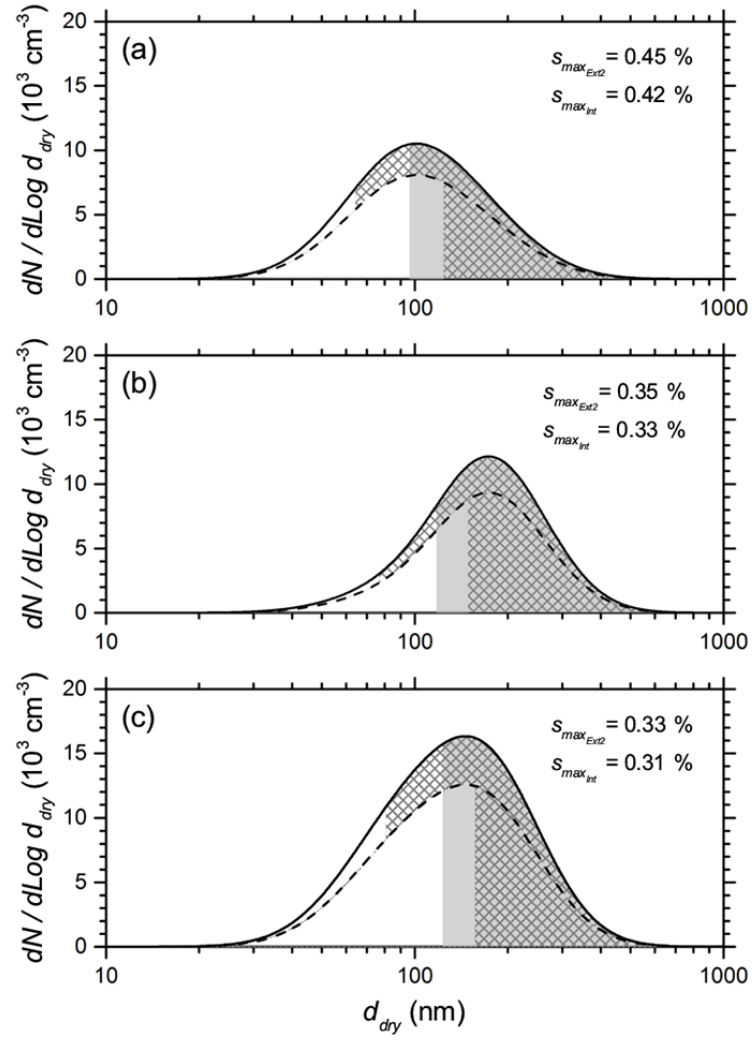

Figure 4. Schematic number size distribution of particles activated in $\mathrm{Ext}_{2}$ (hatched area) and Int (grey area) mixing states, for an average $\kappa_{\mathrm{p}_{\text {eff }}}=0.10$ and $W=5 \mathrm{~m} \mathrm{~s}^{-1}$, for (a) $\mathrm{MP}_{5,1}$, (b) $\mathrm{MP}_{1,5}$ and (c) $\mathrm{HP}_{5,5}$ case studies. Total aerosol population (black, solid line), hygroscopic group $\kappa_{\mathrm{p}}=0.04$ (black, dashed line) and maximum supersaturation reached in the simulations for each mixing state are indicated.

group $\left(\kappa_{\mathrm{p}}=0.30\right)$ was indeed activated as $\mathrm{CCN}$ in the externally mixed $\mathrm{Ext}_{2}$ but was not in the internal mixing, since the internally mixed population $\kappa_{\mathrm{p}_{\mathrm{eff}}}$ is lower and thus the cut size for activation in the internally mixed population is larger. However, an even larger fraction of the particles in the VLH group were not activated in the external mixing, but these were considered as activated when an internal mixing state was assumed. Thus, in this example, and characteristically in the conducted simulations, assuming internal mixing for an externally mixed population led to an overestimation of $N_{\mathrm{d}}$.

Box plots on top of data in Fig. 5 display the magnitude of the overestimation in $N_{\mathrm{d}}$ if internal mixing is assumed for an externally mixed population, for the range of updraft velocities and $\kappa_{\mathrm{p}_{\text {eff }}}$. The overestimation of $N_{\mathrm{d}}$ was expressed as $N_{\mathrm{d}, \text { Int }} / N_{\mathrm{d} \text {,Ext }}-1$, where $N_{\mathrm{d}, \text { Int }}$ and $N_{\mathrm{d} \text {,Ext }}$ refer to estimations for internally and externally mixed populations, respectively, and the population is considered to be externally mixed. Overestimations of $N_{\mathrm{d}}$ when assuming internal mixing were larger when the module of the difference between the internal mixture $\kappa_{\mathrm{p}_{\mathrm{eff}}}$ and that of the hygroscopic group 

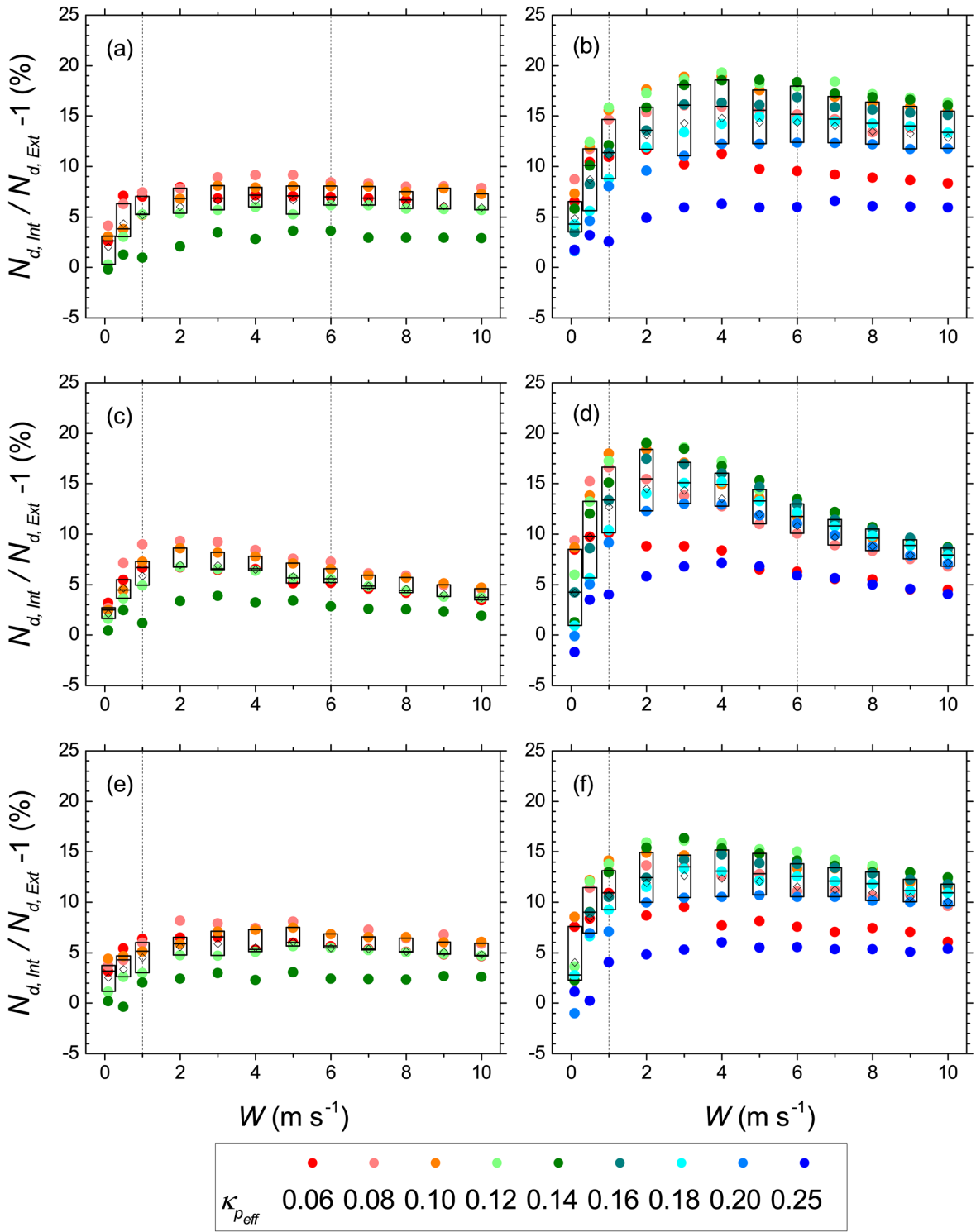

Figure 5. Overestimation of $N_{\mathrm{d}}$ when the aerosol is assumed internally mixed, calculated as a function of the hygroscopicity (color scale) and the updraft velocity, for the external mixing Ext 1 (left) and Ext 2 (right). Plots on panels (a, b), (c, d) and (e, f) correspond to MP 5,1 , $\mathrm{MP}_{1,5}$ and $\mathrm{HP}_{5,5}$ case studies, respectively. Box plots on top of data represent the spread for different hygroscopicity parameters. The box boundaries delimitate the interquartile range and mean values are indicated by diamond symbols. Dashed lines represent the approximate boundaries between $\mathrm{CCN}$ activation regimes.

with closest value of hygroscopicity in the external mixture was greater, i.e., when the internally mixed assumption was comparatively less valid. Overestimations close to the lower limit or below the interquartile range of $\mathrm{CCN}$ overestimations were obtained for populations with fractions $f_{\kappa_{\mathrm{p}}}=0.16 \geq 0.67$ in the $\operatorname{Ext}_{1}$ (with a resulting $\kappa_{\mathrm{p}_{\text {eff }}} \geq 0.12$ ), and $f_{\kappa_{\mathrm{p}}=0.30 \geq}$ 0.62 in the Ext $_{2}$ mixing $\left(\kappa_{\mathrm{p}_{\text {eff }}} \geq 0.2\right)$. Within the aerosoland updraft-sensitive regime, the overestimations of $N_{\mathrm{d}}$ were largest for all three cases. The higher number concentration of particles in the Aitken mode in the $\mathrm{MP}_{5,1}$ and $\mathrm{HP}_{5,5}$ case studies resulted in larger overestimations in the $\mathrm{CCN}$ number concentrations even for the upper range of updraft velocities. In contrast, the overestimations of $N_{\mathrm{d}}$ decreased noticeably as the updraft velocity increased towards the aerosol-limited regime for the $\mathrm{MP}_{1,5}$ case. Within the updraft-limited regime the typically low fractions of activated particles, as well as the estimations of $N_{\mathrm{d}, \text { Int }} / N_{\mathrm{d}, \mathrm{Ext}}-1$, were more susceptible to inaccuracies due to bin resolution.

Average overestimations of $N_{\mathrm{d}}$ for the externally mixed population $\mathrm{Ext}_{1}$ were typically low, $5.7 \pm 2.4,5.1 \pm 2.1$ and $2.9 \pm 2.0 \%$, or the $\mathrm{MP}_{5,1}, \mathrm{MP}_{1,5}$ and $\mathrm{HP}_{5,5}$ case studies. For population $\mathrm{Ext}_{2}$, and the same case studies, averages 
were slightly higher, $12.4 \pm 4.7,10.4 \pm 4.5$ and $10.5 \pm 3.8 \%$, respectively. However, with particle number concentrations of $10000 \mathrm{~cm}^{-3}$ in the $\mathrm{HP}_{5,5}$ case and $6000 \mathrm{~cm}^{-3}$ in the $\mathrm{MP}_{5,1}$ and $\mathrm{MP}_{1,5}$ case studies, the absolute overestimations $\left(N_{\mathrm{d}, \text { Int }}-N_{\mathrm{d} \text {,Ext }}\right)$ in the CCN number concentration for these cases were, respectively, $160 \pm 94,181 \pm 96$ and $224 \pm 137 \mathrm{~cm}^{-3}$ for Ext $_{1}$ simulations and $349 \pm 203$, $358 \pm 188$ and $467 \pm 272 \mathrm{~cm}^{-3}$ for $\mathrm{Ext}_{2}$. Maximum absolute overestimations were reached for higher updrafts, for which the $N_{\mathrm{d}} / N_{\mathrm{a}}$ fraction was higher for all mixing states. For Ext ${ }_{1}$ simulations, the maximum absolute overestimations were 304,323 and $432 \mathrm{~cm}^{-3}$ for the $\mathrm{MP}_{5,1}, \mathrm{MP}_{1,5}$ and $\mathrm{HP}_{5,5}$ cases, respectively, while in $\mathrm{Ext}_{2}$ simulations for the same study cases they were of 637,642 and $838 \mathrm{~cm}^{-3}$. The high aerosol number concentrations considered here, although characterizing polluted conditions like those that could be found in regional hazes in the Amazonia region, are still moderate in comparison with concentrations inside pyrocumulus.

It is important to note that, were the maximum supersaturations achieved in simulations for both mixing states to be the same, $N_{\mathrm{d}}$ would be higher in the internal mixing case simulations and the $\mathrm{CCN}$ overestimations derived from assuming internal mixing would be larger. This difference in the achieved maximum supersaturations does not explain the much smaller impact of mixing state found for cloud parcel model results when compared to those obtained for equilibrium conditions and prescribed supersaturations, but is likely to contribute to it since, in the latter, the same maximum supersaturation is assumed in the estimation of $N_{\mathrm{d}}$ for the different mixing states.

For Amazon smoke particles, these results indicate an overestimation in $N_{\mathrm{d}}$ derived from assuming internal mixing overestimation for an externally mixed population that is below $10 \%$ for all conditions.

\subsection{Hygroscopicity}

The behavior of the CCN activation, as hygroscopicity changed, was distinctly different for the different mixing states. When the population was assumed to be internally mixed, the mean average sensitivity to hygroscopicity, $S_{\kappa_{\mathrm{p}}}$, was low for the case $\mathrm{MP}_{5,1}(0.20)$, and very low for $\mathrm{MP}_{1,5}$ $(0.10)$ and $\mathrm{HP}_{5,5}(0.12)$ case studies. These estimations are in good agreement with those by Reutter et al. (2009) and Ward et al. (2010). For the externally mixed population, however, $\ln -\ln$ curves were far apart from a linear behavior and it was not possible to achieve linear fits. Obtained adjusted $R^{2}$ parameters were close to zero or negative and hence average sensitivities for externally mixed populations were not estimated.

Local sensitivities for the internal mixing state typically decreased as the hygroscopicity parameter increased, starting from median values of $\sim 0.35$ for the $\mathrm{MP}_{5,1}$ case study and of $\sim 0.20$ for the $\mathrm{MP}_{1,5}$ and $\mathrm{HP}_{5,5}$ case studies (Fig. 6)
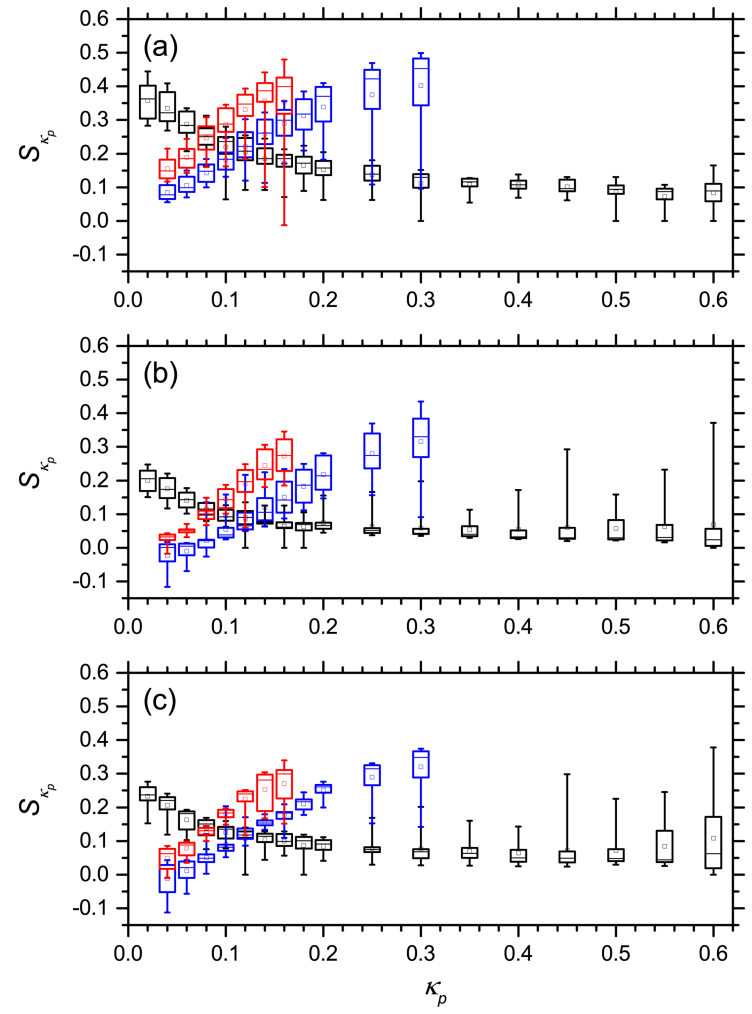

Figure 6. Box-and-whisker plots of the sensitivity $S_{\kappa_{\mathrm{p}}}$ of $N_{\mathrm{d}}$ to the hygroscopicity parameter $\kappa_{\mathrm{p}}$, showing spread of results for updraft velocities between 0.1 and $10 \mathrm{~m} \mathrm{~s}^{-1}$, for (a) $\mathrm{MP}_{5,1}$, (b) $\mathrm{MP}_{1,5}$ and (c) $\mathrm{HP}_{5,5}$ case studies. Box bounds show the interquartile range, the mean value is indicated by a small square, and whiskers delimitate minimum and maximum values. Results for the internally mixed Int and externally mixed populations Ext $_{1}$ and Ext 2 are plotted in black, red and blue, respectively.

until almost stabilizing at values close to $0.15,0.05$ and 0.10 for the same cases for values of $\kappa_{\mathrm{p}}$ within the medium and high hygroscopicity ranges. Notable exceptions were found within the updraft-limited regime for populations with high hygroscopicity where the impact of kinetic effects was high, as will be addressed later in Sect. 4.3. Except for cases within the updraft-limited regime, where kinetic limitations were significant, we found that the impact of the hygroscopicity parameter in $N_{\mathrm{d}}$ was very low for internally mixed populations and $\kappa_{\mathrm{p}}$ within the $\mathrm{MH}$ or the $\mathrm{HH}$ ranges, while for $\kappa_{\mathrm{p}}$ values within the VLH range the impact was low to moderate, in agreement with results obtained by previous studies (Dusek et al., 2006; McFiggans et al., 2006; Reutter et al., 2009; Ward et al., 2010).

On the other hand, the local $S_{\kappa_{\text {peff }}}$ for the externally mixed populations presented mean values (over results for different updraft velocities) that increased with $\kappa_{\mathrm{p}_{\text {eff }}}$ from very low or even negative to values between 0.3 and 0.45 for the highest $\kappa_{\mathrm{p}_{\text {eff }}}$ values (Fig. 6). This higher sensitivity of $N_{\mathrm{d}}$ to $\kappa_{\mathrm{p}_{\text {eff }}}$ in the external mixtures is also apparent in the step increase 
in $N_{\mathrm{d}}$ obtained for the external mixing results for the larger average $\kappa_{\mathrm{p}_{\text {eff }}}$ values (Fig. 2, bottom).

The increasing $S_{\kappa_{\text {peff }}}$ for external mixing cases can be illustrated through the consideration of the following example for the $\mathrm{HP}_{5,5}$ case and an updraft velocity $W=5 \mathrm{~m} \mathrm{~s}^{-1}$. In the internally mixed population with $\kappa_{\mathrm{p}}=0.30,62 \%$ of the total $N_{\mathrm{d}}$ was activated. If the internally mixed population has, instead, $\kappa_{\mathrm{p}}=0.25$, the resulting $N_{\mathrm{d}} / N_{\mathrm{a}}$ fraction is $\sim 61 \%$. However, if the population with $\kappa_{\mathrm{p}_{\text {eff }}}=0.25$ is instead externally mixed, the fraction of particles with $\kappa_{\mathrm{p}}=0.30$ that reached activation increased to $67 \%$, but, of the particles with $\kappa_{\mathrm{p}}=0.04$ (19\% of total population), only $22 \%$ reached activation. Consequently, even when the MH particles predominated, the resulting ratio was $58 \%$, a more significant decrease from the case with $\kappa_{\mathrm{p}}=0.30$ than in the internally mixed population case.

Considering the results from the simulations and the little variability and low values of $S_{\kappa_{\mathrm{p}_{\text {eff }}}}$ for internally mixed populations, variations in hygroscopicity within the $\mathrm{MH}$ and $\mathrm{HR}$ could be considered instead as secondary and neglected, especially if the difference in hygroscopicity is not large, since the level of sophistication within GCMs should be kept at a minimum whenever the accuracy of results is not compromised. When the hygroscopicity is within the LH and VLH, however, the overestimation in the activated fraction might also be substantial, as illustrated in Fig. 7 for updraft velocities in the updraft- and aerosol-sensitive regime, for internally mixed populations. In the extreme case when $\kappa_{\mathrm{p}}=0.20$ was assumed for a population of $\kappa_{\mathrm{p}}=0.04$, the mean overestimation of the $\mathrm{CCN}$ population for the $\mathrm{MP}_{5,1}, \mathrm{MP}_{1,5}$ and $\mathrm{HP}_{5,5}$ was $54.3 \pm 3.7,22.4 \pm 1.4$ and $26.6 \pm 2,3 \%$, respectively. In comparison, if $\kappa_{\mathrm{p}}=0.60$ was presumed for aerosols with $\kappa_{\mathrm{p}}=0.20$, the mean overestimations of $N_{\mathrm{d}}$ obtained for the $\mathrm{MP}_{5,1}, \mathrm{MP}_{1,5}$ and $\mathrm{HP}_{5,5}$ cases and the same range of updraft velocities were $15.5 \pm 1.6,4.8 \pm 0.3$ and $6.4 \pm 0.8 \%$, respectively.

A significant overestimation of $N_{\mathrm{d}}$ can thus result from assuming a hygroscopicity in the $\mathrm{MH}$ range for the Amazon smoke aerosols. These results suggest that larger values of $\kappa_{\mathrm{p}}$ like those recommended for continental aerosol or biomass burning particles in other regions of the world are not adequate to describe the $\mathrm{CCN}$ activation behavior of Amazon smoke particles.

\subsection{Kinetic limitations}

Temporal series of the $\mathrm{CCN}$ activation with resolutions of 0.5 and $1 \mathrm{~s}$ near the time of maximum supersaturation for strong and low to moderate updrafts, respectively, were used to analyze the particle growth and activation evolution in time. Three separate effects in the evolution of $N_{\mathrm{d}}$ were observed in the simulations for weak and sometimes even moderate updrafts that could be attributed to the effect of kinetic limitations: (1) a delay between the time when maximum supersaturation was reached and the time when the activated

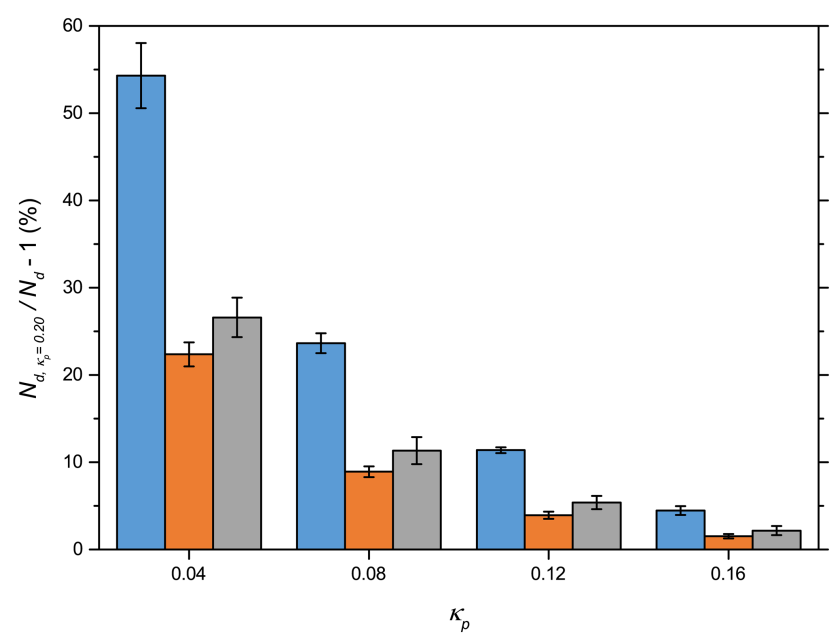

Figure 7. Overestimation of $N_{\mathrm{d}}$ (mean \pm standard deviation over the updraft velocities in the updraft- and aerosol-sensitive regime) when $\kappa_{\mathrm{p}}=0.20$ is assumed, as a function of the population $\kappa_{\mathrm{p}}$. Results correspond to $\mathrm{MP}_{5,1}$ (blue), $\mathrm{MP}_{1,5}$ (orange) and $\mathrm{HP}_{5,5}$ (grey) case studies for an internally mixed population.

fraction is largest; (2) a decrease in the number of activated particles with cloud depth after the maximum activated fraction is reached; and, finally, (3) a overestimation of $N_{\mathrm{d}}$ if assuming that equilibrium applies.

The delay in activation was amplified with the increase in the particle $\kappa_{\mathrm{p}_{\mathrm{eff}}}$. A relation to particle size and number concentration was also apparent, being the delay longest for the $\mathrm{HP}_{5,5}$ case, moderate in the $\mathrm{MP}_{1,5}$ case, and much shorter for the $\mathrm{MP}_{5,1}$ case, also for large $\kappa_{\mathrm{p}_{\text {eff }}}$ values and weak updrafts. This is illustrated in Fig. 8 for an internally mixed population and $W=0.5 \mathrm{~m} \mathrm{~s}^{-1}$. Due to the delay in activation a significant fraction of particles was typically not activated at the time maximum supersaturation was reached. Within the updraft-limited regime, the delay in the activation was such that at the time of maximum supersaturation no particles are activated for internally mixed populations with $\kappa_{\mathrm{p}_{\text {eff }}}$ above a certain threshold. For an updraft velocity of $=0.5 \mathrm{~m} \mathrm{~s}^{-1}$, this threshold was $\kappa_{\mathrm{p}_{\text {eff }}}=0.50$ for the $\mathrm{MP}_{5,1}$ case and $\kappa_{\mathrm{p}_{\text {eff }}}=0.35$ for the $\mathrm{MP}_{1,5}$ and $\mathrm{HP}_{5,5}$ cases. In the $\mathrm{MP}_{1,5}$ case, for an updraft velocity $W=3 \mathrm{~m} \mathrm{~s}^{-1}$, already in the updraft- and aerosol-sensitive regime, the threshold was still $\kappa_{\mathrm{p}_{\text {eff }}}=0.35$. The maximum value of $N_{\mathrm{d} \text {,neq }}$ simp was also reached sometime after the maximum supersaturation is reached, and its value was slightly higher than the maximum of $N_{\mathrm{d} \text {,neq. }}$. However, the strong kinetic effects obtained for the larger $\kappa_{\mathrm{p}_{\text {eff }}}$ values near the time of maximum supersaturation for $N_{\mathrm{d} \text {,neq }}$ were not as strong for $N_{\mathrm{d}, \text { neq }}$ simp . After the maximum $N_{\mathrm{d} \text {,neq }}$ is reached, however, differences between both estimations are below $1 \%$ and at the end of the simulation both estimations are very similar. The fraction of particles not strictly activated in $N_{\mathrm{d}, \text { neq }}$ was important only near the time of maximum supersaturation, indicating that this assumption has no influ- 

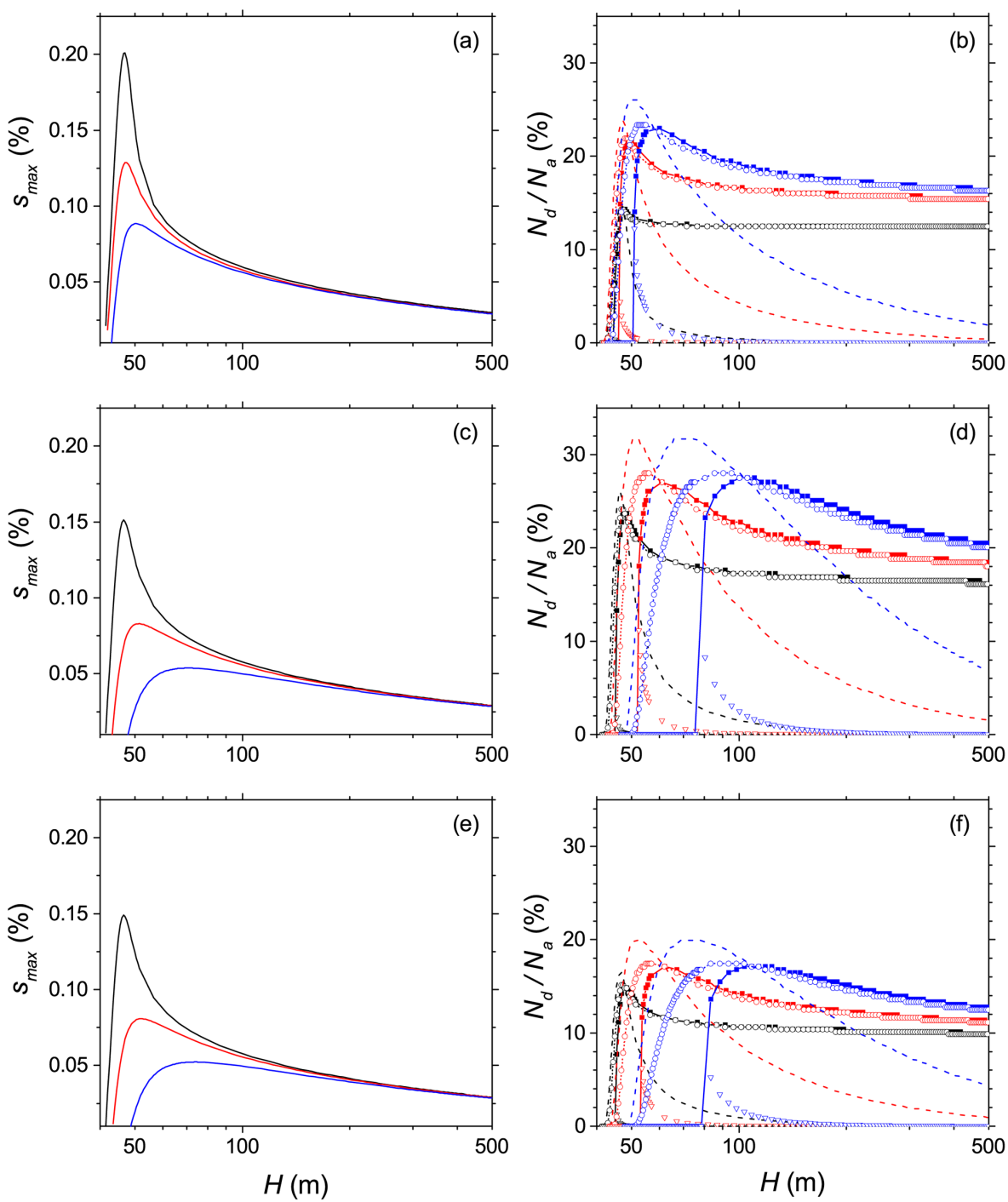

Figure 8. Supersaturation (left) and aerosol activated fraction (right) as a function of cloud height for an internally mixed population with $\kappa_{\mathrm{p}}=0.06$ (black), $\kappa_{\mathrm{p}}=0.25$ (red) and $\kappa_{\mathrm{p}}=0.60$ (blue), and $W=0.5 \mathrm{~m} \mathrm{~s}^{-1}$. The cloud droplet concentration was estimated as either $N_{\mathrm{d} \text {,eq }}$

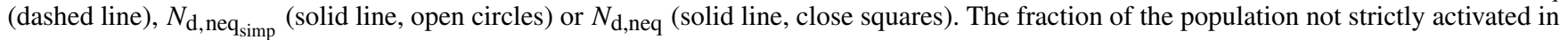
$N_{\text {d,neq }}$ is indicated (open downward-facing triangles). Plots on panels (a, b), (c, d) and (e, f) correspond to $\mathrm{MP}_{5,1}, \mathrm{MP}_{1,5}$ and $\mathrm{HP}_{5,5}$ case studies, respectively.

ence in results presented in previous sections, where cloud droplet concentrations were estimated at the end of the simulation. However, the differences near the time of maximum supersaturation would be larger if this fraction is disregarded.

For the externally mixed population $\operatorname{Ext}_{1}$, although $N_{\mathrm{d} \text {,neq }}$ was significantly lower than $N_{\mathrm{d} \text {,eq }}$ for weak updrafts, in all the cases at least a fraction of particles was activated at the time of maximum supersaturation. For $\mathrm{Ext}_{2}$ and $W=0.5 \mathrm{~m} \mathrm{~s}^{-1}$, however, populations with $\kappa_{\mathrm{p}_{\text {eff }}} \geq 0.12$, or $f_{\kappa_{\mathrm{p}}}=0.30 \geq 0.31$, also showed $N_{\mathrm{d}, \text { neq }}=0$ for both $\mathrm{MP}_{1,5}$ and $\mathrm{HP}_{5,5}$ cases at the time of maximum supersaturation. This is exemplified in Fig. 9 for three values of the effective hygroscopicity parameter. Interestingly enough, particles from both hygroscopic groups failed to activate in these conditions. The value of maximum supersaturation was very low in these cases, and it is likely that particles in the more hygroscopic group condense the limited water vapor on their surfaces more readily, although not in great enough quantities as to activate themselves, but limiting the water vapor available to less hygroscopic particles even more and preventing their activation as well. Particles from both groups seem to grow rather slowly, and both groups appear to activate at the same time.

As moderate and strong updrafts were considered, the delay between maximum supersaturation and maximum activation reduced until no longer observed at the temporal res- 

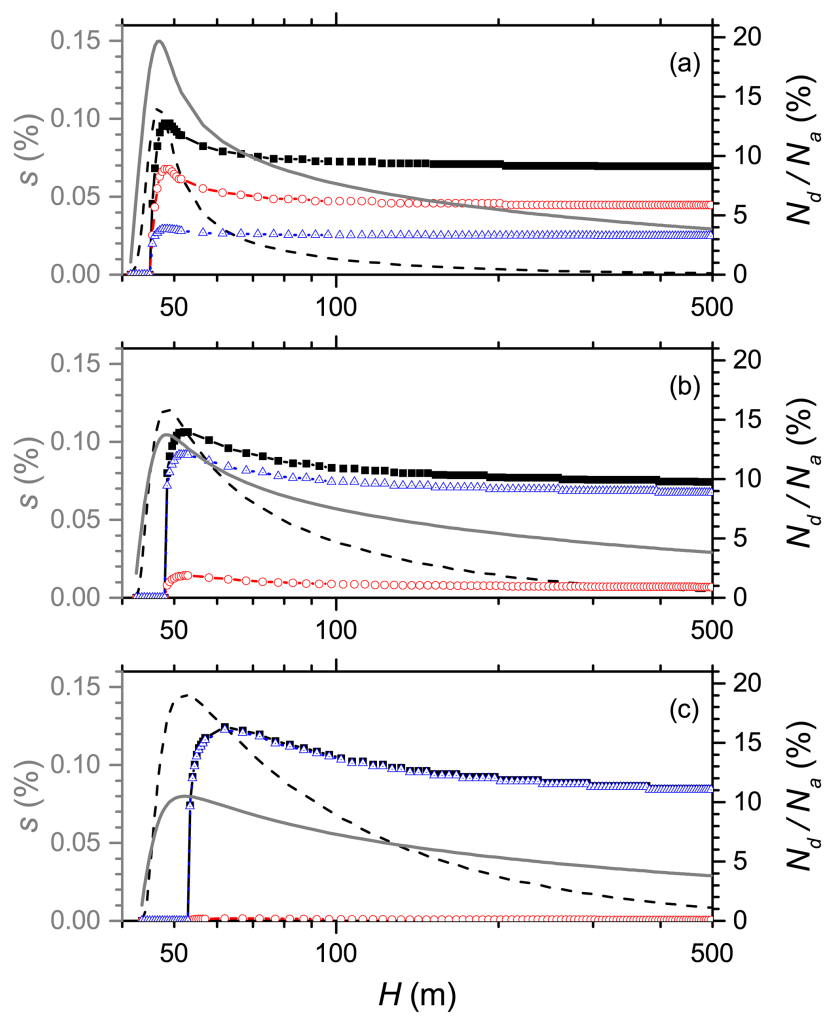

Figure 9. Supersaturation (left axis, grey) and aerosol activated fraction during the simulation (right axis) for the Ext 2 population and the $\mathrm{HP}_{5,5}$ case study, for $W=0.5 \mathrm{~m} \mathrm{~s}^{-1}$ and $\kappa_{\mathrm{p}_{\text {eff }}}=0.06$ (a), $\kappa_{\mathrm{p}_{\mathrm{eff}}}=0.14$ (b) and $\kappa_{\mathrm{p}_{\mathrm{eff}}}=0.25$ (c). The cloud droplet concentration was estimated as $N_{\mathrm{d} \text {,eq }}$ (dashed line), and $N_{\mathrm{d} \text {,neq }}$ for the population (black solid line, close squares) and hygroscopic groups with $\kappa_{\mathrm{p}}=0.04$ (red dashed line, open circles) and $\kappa_{\mathrm{p}}=0.30$ (blue dotted line, open upward-facing triangles).

olution of the time series. Within the updraft-limited regime, the mean overestimation of $N_{\mathrm{d} \text {,neq }}$ in comparison with $N_{\mathrm{d} \text {,eq }}$ over the range of $\kappa_{\text {peff }}$, excluding those that led to $N_{\text {d,neq }}=0$, ranged from $\sim 10$ to $\sim 100 \%$ in internally mixed populations, and between $\sim 10$ and $\sim 250 \%$ in externally mixed ones (Fig. 10), being larger for the higher values of $\kappa_{\mathrm{p}_{\text {eff }}}$. However, for all case studies and mixing states, the overestimation at the time of maximum supersaturation was typically below $12 \%$ within the updraft- and aerosol-sensitive, and below $5 \%$ within the aerosol-limited regime.

The overestimation of $N_{\mathrm{d} \text {,neq }}$ at the time of maximum supersaturation if assuming equilibrium applies can be explained by the evaporation mechanism. However, as the cloud depth increases, and in particular at the defined end of the simulation, the deactivation mechanism can be more relevant. Although $N_{\mathrm{d} \text {,neq }}$ was always lower at the end of the simulation than at its maximum, the difference was typically low, between 2 and $10 \%$ for most updraft velocities and mixing states, as evidenced in the similar overestimations of both values by $\max \left(N_{\mathrm{d}, \text { eq }}\right)$. Both evaporation and deactiva- tion mechanisms were relevant for weak and even moderate updrafts, and a relation with particle size and number concentration was apparent, as previously reported by Nenes et al. (2001) for ammonium sulfate particles. Our results are also consistent with the reduction in the droplet concentrations of up to $35 \%$ due to kinetic limitations found by Roberts et al. (2003) for updrafts of $0.1 \mathrm{~m} \mathrm{~s}^{-1}$ and aerosol data corresponding to the dry season in Amazonia.

In our results, the effects of kinetic limitations were strong when a significant fraction of particles with hygroscopicity in the $\mathrm{MH}$ or $\mathrm{LH}$ range was present. However, for particles with low and very low hygroscopicities like the Amazon smoke particles, kinetic limitations were less important, even if large aerosol loads were present.

A relation between the timescale of solubility and the $\mathrm{CCN}$ activation behavior of aerosols is known (Chuang, 2006), and several studies have analyzed kinetic limitations by comparing the aerosol particles' growth and that of a calibration aerosol with a high solubility and the same critical supersaturation, with mixed conclusions regarding the importance of this process to CCN activation (Bougiatioti et al., 2011; Engelhart et al., 2008; Padró et al., 2012; Raatikainen et al., 2012; Ruehl et al., 2007). However, at the low supersaturations reached as a result of the weak updraft velocity and the large aerosol loads considered, the kinetic limitations discussed in this study derive more likely from the differences in water uptake and critical supersaturation due to the particle hygroscopicity.

\section{Conclusions}

The available data on smoke particles in the Amazon region (Sect. 3) suggest that this aerosol population has a rather consistent size and that external mixing of two particle groups having very low and low hygroscopicity, respectively, is typical for this aerosol population. We conducted cloud model simulations using three hypothetical case studies and a variety of hygroscopicities and mixing states that resembled typical conditions found in the literature for smoke aerosols in the Amazon in moderate to highly polluted conditions. Simulations were conducted for these three case studies to estimate the effect of different values of hygroscopicity and mixing state, including those conditions that resemble observed data for smoke particles $\left(\mathrm{Ext}_{1}\right)$. The impact of kinetic limitations was assessed.

The impact in the surface tension due to the organic material present in smoke aerosols is likely to be relevant (Fors et al., 2010; Giordano et al., 2013), but was not included in this work due to the complex organic composition of these particles that lead to difficulties for its modeling. We consider this a limitation of our results that should be addressed in future works.

A low sensitivity of the cloud droplet number concentration $N_{\mathrm{d}}$ to the population effective hygroscopicity parameter 

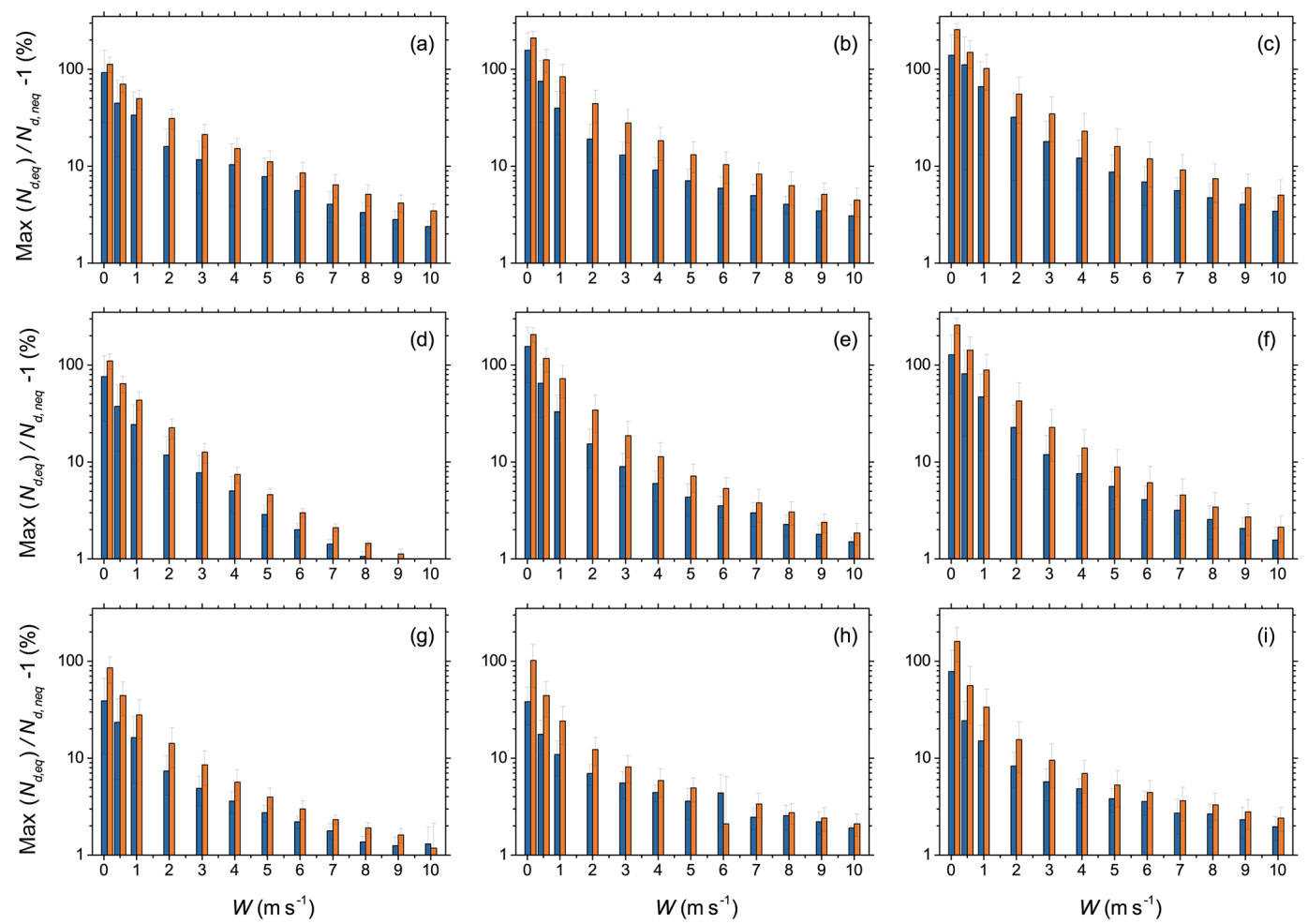

Figure 10. Overestimation of $N_{\mathrm{d}}$ when the population is estimated assuming equilibrium at the time of maximum supersaturation, $\max \left(N_{\mathrm{d} \text {,eq }}\right)$, compared with $N_{\mathrm{d} \text {,neq }}$ at the time of maximum supersaturation (blue) and at the end of the simulation (orange), for the range of updraft velocities. Values correspond to the $\mathrm{MP}_{5,1}(\mathbf{a}-\mathbf{c}), \mathrm{MP}_{1,5}(\mathbf{d}-\mathbf{f})$ and $\mathrm{HP}_{5,5}(\mathbf{g}-\mathbf{i})$ case studies. The mixture of the aerosol population was either internal (left panels) or external as in Ext $_{1}$ (middle panels) and $\mathrm{Ext}_{2}$ (right panels)

$\kappa_{\mathrm{p}_{\mathrm{eff}}}$ was found for medium and large hygroscopicity when the population was internally mixed. However, for particles with hygroscopicity in the lower range of $\kappa_{\mathrm{p}_{\text {eff }}}(<0.20)$, the effective hygroscopicity of smoke particles for the Amazon appears to stand in the VLH and LH ranges, where the sensitivity to this parameter was found to be moderate. Therefore, $N_{\mathrm{d}}$ could be overestimated significantly if larger values of hygroscopicity, like those suggested for biomass burning particles elsewhere, were to be used for Amazonia smoke particles.

Hygroscopic mixing state in the conducted cloud model simulations led to differences lower than those obtained in previous studies that addressed mixing state for equilibrium conditions and prescribed supersaturations. In particular, the overestimation of $N_{\mathrm{d}}$ was low for populations similar in hygroscopicity to the Amazon smoke aerosols $\left(\mathrm{Ext}_{1}\right.$ in the simulations), but slightly higher when the external mixing was between groups with VLH and MH (Ext 2$)$.

The parameter $\kappa_{\mathrm{p}_{\text {eff }}}$ posed a much larger impact on the $\mathrm{CCN}$ activation within the MH range for externally mixed populations than for internally mixed ones, even for low fractions of VLH aerosols. When $\kappa_{\mathrm{p}_{\mathrm{eff}}}$ is estimated assuming internal mixing, and in particular when particles of VLH are present, it is important to take into account that the typically low sensitivity to hygroscopicity of internally mixed populations does not apply and even relatively small variabilities in $\kappa_{\text {peff }}$ could affect the CCN activation behavior of the population. Consequently, assuming internal mixing of particles with very low and low-hygroscopicity particles with moderate or large hygroscopicity should be avoided.

Finally, kinetic limitations were found to be much lower for particles within VLH and LH hygroscopic groups, and therefore its impact on the $\mathrm{CCN}$ behavior of Amazon smoke particles is expected to be limited, in spite of the presence of large aerosol loads.

The inclusion of mixing state, adequate hygroscopicity values and the consideration of kinetic limitations into global and regional circulation model are all possible, although in many cases at a computational cost. The choice of using two separate aerosol populations to account for the externally mixing character of the biomass burning population will increase the computational burden of the model, and the modeler might choose instead to consider biomass burning aerosols as only one population internally mixed and externally mixed with other aerosol populations, given that the overestimation derived from this choice is not significant. Global models or regional models over a large domain should specify, if possible, the aerosol hygroscopicity for different 
regions, in particular when values in the very low or low range of hygroscopicity are to be considered. Also, for Amazonia smoke aerosols, the choice of a parameterization that accounts for kinetic limitations, typically more demanding in terms of computational resources, might not improve results significantly over a parameterization that does not account for their impact.

\section{Data availability}

The cloud model used can be made available upon request, as well as the maximum supersaturations and activated fractions obtained for each condition. Full solutions for the ODE system are also available but in a machine-dependent format. Please contact the correspondence author. 


\section{Appendix A: Nomenclature of frequently used symbols}

$\mathrm{CCN} \quad$ Cloud condensation nuclei

dry,c Particle cut diameter for activation (dry)

$f_{\mathrm{hg}} \quad$ Number fraction of hygroscopic group (hg)

$N_{\mathrm{a}} \quad$ Aerosol number concentration

$N_{\mathrm{d}} \quad$ Cloud droplet number concentration

$N_{\text {d,eq }} \quad N_{\mathrm{d}}$ estimated assuming equilibrium conditions

$N_{\mathrm{d}, \text { neq }} \quad N_{\mathrm{d}}$ estimated without assuming equilibrium conditions

$s \quad$ Supersaturation

$s_{\max } \quad$ Cloud maximum supersaturation

$S_{X_{i}} \quad$ Sensitivity of $N_{\mathrm{d}}$ to the parameter $X_{i}$

$t \quad$ Time

$T \quad$ Temperature

$W \quad$ Cloud parcel updraft velocity

$\kappa_{\mathrm{p}} \quad$ Specific hygroscopicity parameter by Petters and Kreidenweis (2007)

$\kappa_{\mathrm{p}_{\text {eff }}} \quad$ Population effective specific hygroscopicity parameter
Appendix B: Simplified Köhler equation and estimation of the cut diameter for $\mathrm{CCN}$ activation

For an aerosol particle with dry diameter $d_{\text {dry }}$ formed by a soluble fraction and an insoluble core, the Köhler equation can be approximated by the expression (Pruppacher and Klett, 1997)

$s \approx \frac{A}{d}-\frac{B d_{\mathrm{dry}}{ }^{3}}{d^{3}-d_{\mathrm{dry}}{ }^{3}}$,

where $s$ is the supersaturation, $d$ is the particle wet diameter, and terms $A$ and $B$ are parameters in the curvature and solute terms of the Köhler equation. In this work, $B$ was assumed to be identical to the parameter $\kappa_{\mathrm{p}}$ for all values of $\kappa_{\mathrm{p}}$ and $s$.

It can be shown (Pruppacher and Klett, 1997) that the particle cut wet diameter for activation $d_{\mathrm{c}}$ can be estimated as

$d_{\mathrm{c}}=-D+\left(D^{2}-E\right)^{1 / 2}$,

where the parameters $D$ and $E$ are estimated as

$D=\frac{B^{2} A-3 B A s}{3 B s^{2}-3 B^{2} s}$

and

$E=\frac{3 B A^{2}}{3 B s^{2}-3 B^{2} s}$.

Finally, the corresponding dry diameter of the smallest activated particle, $d_{\mathrm{dry}, \mathrm{c}}$, can be calculated as

$d_{\mathrm{dry}, \mathrm{c}}^{3}=\frac{d_{\mathrm{c}}^{3}\left(A-s d_{\mathrm{c}}\right)}{A+(B-s) d_{\mathrm{c}}}$. 


\section{The Supplement related to this article is available online at doi:10.5194/acp-17-2373-2017-supplement.}

Competing interests. The authors declare that they have no conflict of interest.

Acknowledgements. The authors thank three anonymous referees for their valuable suggestions and comments that contributed significantly to the improvement of the present paper. This work was supported by the São Paulo Research Foundation (FAPESP), through the projects 2012/13575-9, DR 2012/09934-3, BEPE 2013/02101-9 and BPE 2014/01564-8.

Edited by: H. Coe

Reviewed by: three anonymous referees

\section{References}

Abdul-Razzak, H. and Ghan, S.: A parameterization of aerosol activation: 2. Multiple aerosol types, J. Geophys. Res., 105, 68376844, 2000.

Abdul-Razzak, H. and Ghan, S. J.: A parameterization of aerosol activation: 3. Sectional representation, J. Geophys. Res, 107, 4026, 10.1029/2001JD000483, 2002.

Almeida, G. P., Brito, J., Morales, C. A., Andrade, M. F., and Artaxo, P.: Measured and modelled cloud condensation nuclei $(\mathrm{CCN})$ concentration in São Paulo, Brazil: the importance of aerosol size-resolved chemical composition on CCN concentration prediction, Atmos. Chem. Phys., 14, 7559-7572, doi:10.5194/acp-14-7559-2014, 2014.

Andreae, M.: Biomass burning: its history, use, and distribution and its impact on environmental quality and global climate, MIT Press, 3-21, 1991.

Andreae, M. O., Artaxo, P., Fischer, H., Freitas, S. R., Grégoire, J.-M., Hansel, A., Hoor, P., Kormann, R., Krejci, R., Lange, L., Lelieveld, J., Lindinger, W., Longo, K., Peters, W., de Reus, M., Scheeren, B., Silva Dias, M. A. F., Ström, J., van Velthoven, P. F. J., and Williams, J.: Transport of biomass burning smoke to the upper troposphere by deep convection in the equatorial region, Geophys. Res. Lett., 28, 951-954, doi:10.1029/2000GL012391, 2001.

Andreae, M. O., Rosenfeld, D., Artaxo, P., Costa, A. A., Frank, G. P., Longo, K. M., and Silva-Dias, M. A. F.: Smoking rain clouds over the Amazon, Science, 303, 1337-1342, doi:10.1126/science.1092779, 2004

Artaxo, P., Rizzo, L. V., Brito, J. F., Barbosa, H. M. J., Arana, A., Sena, E. T., Cirino, G. G., Bastos, W., Martin, S. T., and Andreae, M. O.: Atmospheric aerosols in Amazonia and land use change: from natural biogenic to biomass burning conditions, Faraday Discuss., 165, 203-235, doi:10.1039/C3FD00052D, 2013.

Ban-weiss, G. A., Jin, L., Bauer, S. E., Bennartz, R., Liu, X., Zhang, K., Ming, Y., Guo, H., and Jiang, J. H.: Evaluating clouds, aerosols, and their interactions in three global climate models using satellite simulators and observations, J. Geophys. Res.Atmos., 119, 10876-10901, doi:10.1002/2014JD021722, 2014.
Bauer, S. E. and Menon, S.: Aerosol direct, indirect, semidirect, and surface albedo effects from sector contributions based on the IPCC AR5 emissions for preindustrial and present-day conditions, J. Geophys. Res.-Atmos., 117, 1-15, doi:10.1029/2011JD016816, 2012.

Bauer, S. E., Menon, S., Koch, D., Bond, T. C., and Tsigaridis, K.: A global modeling study on carbonaceous aerosol microphysical characteristics and radiative effects, Atmos. Chem. Phys., 10, 7439-7456, doi:10.5194/acp-10-7439-2010, 2010.

Bougiatioti, A., Nenes, A., Fountoukis, C., Kalivitis, N., Pandis, S. N., and Mihalopoulos, N.: Size-resolved CCN distributions and activation kinetics of aged continental and marine aerosol, Atmos. Chem. Phys., 11, 8791-8808, doi:10.5194/acp-11-87912011, 2011.

Brito, J., Rizzo, L. V., Morgan, W. T., Coe, H., Johnson, B., Haywood, J., Longo, K., Freitas, S., Andreae, M. O., and Artaxo, P.: Ground-based aerosol characterization during the South American Biomass Burning Analysis (SAMBBA) field experiment, Atmos. Chem. Phys., 14, 12069-12083, doi:10.5194/acp-1412069-2014, 2014.

Camponogara, G., Silva Dias, M. A. F., and Carrió, G. G.: Relationship between Amazon biomass burning aerosols and rainfall over the La Plata Basin, Atmos. Chem. Phys., 14, 4397-4407, doi:10.5194/acp-14-4397-2014, 2014.

Carrico, C. M., Petters, M. D., Kreidenweis, S. M., Sullivan, A. P., McMeeking, G. R., Levin, E. J. T., Engling, G., Malm, W. C., and Collett Jr., J. L.: Water uptake and chemical composition of fresh aerosols generated in open burning of biomass, Atmos. Chem. Phys., 10, 5165-5178, doi:10.5194/acp-10-5165-2010, 2010

Christensen, S. I. and Petters, M. D.: The role of temperature in cloud droplet activation, J. Phys. Chem. A, 116, 9706-9717, doi:10.1021/jp3064454, 2012.

Chuang, P. Y.: Sensitivity of cloud condensation nuclei activation processes to kinetic parameters, J. Geophys. Res., 111, 1-7, doi:10.1029/2005JD006529, 2006.

Crutzen, P. J. and Andreae, M. O.: Biomass burning in the tropics: impact on atmospheric chemistry and biogeochemical cycles, Science, 250, 1669-78, doi:10.1126/science.250.4988.1669, 1990.

Cubison, M. J., Ervens, B., Feingold, G., Docherty, K. S., Ulbrich, I. M., Shields, L., Prather, K., Hering, S., and Jimenez, J. L.: The influence of chemical composition and mixing state of Los Angeles urban aerosol on CCN number and cloud properties, Atmos. Chem. Phys., 8, 5649-5667, doi:10.5194/acp-8-5649-2008, 2008.

Dusek, U., Frank, G. P., Hildebrandt, L., Curtius, J., Schneider, J., Walter, S., Chand, D., Drewnick, F., Hings, S., Jung, D., Borrmann, S., and Andreae, M. O.: Size matters more than chemistry for cloud-nucleating ability of aerosol particles, Science, 312, 1375-8, doi:10.1126/science.1125261, 2006.

Dusek, U., Frank, G. P., Massling, A., Zeromskiene, K., Iinuma, Y., Schmid, O., Helas, G., Hennig, T., Wiedensohler, A., and Andreae, M. O.: Water uptake by biomass burning aerosol at suband supersaturated conditions: closure studies and implications for the role of organics, Atmos. Chem. Phys., 11, 9519-9532, doi:10.5194/acp-11-9519-2011, 2011.

Engelhart, G. J., Asa-Awuku, A., Nenes, A., and Pandis, S. N.: CCN activity and droplet growth kinetics of fresh and aged monoter- 
pene secondary organic aerosol, Atmos. Chem. Phys., 8, 39373949, doi:10.5194/acp-8-3937-2008, 2008.

Engelhart, G. J., Hennigan, C. J., Miracolo, M. A., Robinson, A. L., and Pandis, S. N.: Cloud condensation nuclei activity of fresh primary and aged biomass burning aerosol, Atmos. Chem. Phys., 12, 7285-7293, doi:10.5194/acp-12-7285-2012, 2012.

Ervens, B., Cubison, M. J., Andrews, E., Feingold, G., Ogren, J. A., Jimenez, J. L., Quinn, P. K., Bates, T. S., Wang, J., Zhang, Q., Coe, H., Flynn, M., and Allan, J. D.: CCN predictions using simplified assumptions of organic aerosol composition and mixing state: a synthesis from six different locations, Atmos. Chem. Phys., 10, 4795-4807, doi:10.5194/acp-10-4795-2010, 2010.

Farmer, D. K., Cappa, C. D., and Kreidenweis, S. M.: Atmospheric Processes and Their Controlling Influence on Cloud Condensation Nuclei Activity, Chem. Rev., 115, 4199-4217, doi:10.1021/cr5006292, 2015.

Feingold, G.: Modeling of the first indirect effect: Analysis of measurement requirements, Geophys, Res, Lett,, 30, 1-4, doi:10.1029/2003GL017967, 2003.

Fors, E. O., Rissler, J., Massling, A., Svenningsson, B., Andreae, M. O., Dusek, U., Frank, G. P., Hoffer, A., Bilde, M., Kiss, G., Janitsek, S., Henning, S., Facchini, M. C., Decesari, S., and Swietlicki, E.: Hygroscopic properties of Amazonian biomass burning and European background HULIS and investigation of their effects on surface tension with two models linking $\mathrm{H}$ TDMA to CCNC data, Atmos. Chem. Phys., 10, 5625-5639, doi:10.5194/acp-10-5625-2010, 2010.

Freitas, S. R., Longo, K. M., Silva Dias, M. A. F., Silva Dias, P. L., Chatfield, R., Prins, E., Artaxo, P., Grell, G. A., and Recuero, F. S.: Monitoring the transport of biomass burning emissions in South America, Environ. Fluid Mech., 5, 135-167, doi:10.1007/s10652-005-0243-7, 2005.

Fromm, M. D. and Servranckx, R.: Transport of forest fire smoke above the tropopause by supercell convection, Geophys. Res. Lett., 30, 1-4, doi:10.1029/2002GL016820, 2003.

Ghan, S. J., Abdul-Razzak, H., Nenes, A., Ming, Y., Liu, X., Ovchinnikov, M., Shipway, B., Meskhidze, N., Xu, J., and Shi, X.: Droplet nucleation: Physically-based parameterizations and comparative evaluation, J. Adv. Model. Earth Sys., 3, 1-33, doi:10.1029/2011MS000074, 2011.

Giordano, M. R., Short, D. Z., Hosseini, S., Lichtenmerg, W., and Asa-Awuku, A. A.: Changes in droplet surface tension affect the observed hygroscopicity of photochemically aged biomass burning aerosol, Environ. Sci. Technol., 47, 1098010986, doi:10.1021/es404971u, 2013.

Granier, C., Bessagnet, B., Bond, T., D’Angiola, A., Denier van der Gon, H., Frost, G. J., Heil, A., Kaiser, J. W., Kinne, S., Klimont, Z., Kloster, S., Lamarque, J.-F., Liousse, C., Masui, T., Meleux, F., Mieville, A., Ohara, T., Raut, J.-C., Riahi, K., Schultz, M. G., Smith, S. J., Thompson, A., Aardenne, J., Werf, G. R., and Vuuren, D. P.: Evolution of anthropogenic and biomass burning emissions of air pollutants at global and regional scales during the 1980-2010 period, Clim. Change, 109, 163-190, doi:10.1007/s10584-011-0154-1, 2011.

Gunthe, S. S., King, S. M., Rose, D., Chen, Q., Roldin, P., Farmer, D. K., Jimenez, J. L., Artaxo, P., Andreae, M. O., Martin, S. T., and Pöschl, U.: Cloud condensation nuclei in pristine tropical rainforest air of Amazonia: size-resolved measurements and modeling of atmospheric aerosol composition and CCN activity,
Atmos. Chem. Phys., 9, 7551-7575, doi:10.5194/acp-9-75512009, 2009.

He, J., Zhang, Y., Glotfelty, T., He, R., Bennartz, R., Rausch, J., and Sartelet, K.: Decadal simulation and comprehensive evaluation of CESM/CAM5.1 with advanced chemistry, aerosol microphysics, and aerosol-cloud interactions, J. Adv. Model. Earth Sys., 7, 110-141, doi:10.1002/2014MS000360, 2015.

Hindmarsh, A. C.: The PVODE and IDA algorithms, Tech. Rep. UCRL-ID-141558, Lawrence Livermore National Laboratory, 2000.

Hindmarsh, A. C. and Taylor, A. G.: User Documentatin of IDA, a differential-algebraic equation solver for sequential and parallel computers, Tech. rep., Lawrence Livermore National Laboratory Report UCRL-MA-136910, 1999.

Hsiao, T.-C., Ye, W.-C., Wang, S.-H., Tsay, S.-C., Chen, W.-N., Lin, N.-H., Lee, C.-T., Hung, H.-M., Chuang, M.-T., and Chantara, S.: Investigation of the CCN Activity, BC and UVBC Mass Concentrations of Biomass Burning Aerosols during the 2013 BASELInE Campaign, Aerosol Air Qual. Res., 16, 2742-2756, doi:10.4209/aaqr.2015.07.0447, 2016.

Hudson, J. G.: Variability of the relationship between particle size and cloud-nucleating ability, Geophys. Res. Lett., 34, 1-5, doi:10.1029/2006GL028850, 2007.

IPCC: Climate Change 2013: The Physical Science Basis, Contribution of Working Group I to the Fifth Assessment Report of the Intergovernmental Panel on Climate Change, Cambridge University Press, Cambridge, UK, New York, NY, USA, 2013.

Jacobson, M.: The short-term cooling but long-term global warming due to biomass burning, J. Climate, 17, 2909-2926, 2004.

Jacobson, M. Z.: Fundamentals of atmospheric modeling, 2nd Edn., Cambridge University Press, Cambridge, Massachussets, 2005.

Kandler, K. and Schütz, L.: Climatology of the average watersoluble volume fraction of atmospheric aerosol, Atmos. Res., 83, 77-92, doi:10.1016/j.atmosres.2006.03.004, 2007.

Köhler, H.: The nucleus in and the growth of hygroscopic droplets, T. Faraday Soc., 32, 1152-1161, 1936.

Lamarque, J.-F., Bond, T. C., Eyring, V., Granier, C., Heil, A., Klimont, Z., Lee, D., Liousse, C., Mieville, A., Owen, B., Schultz, M. G., Shindell, D., Smith, S. J., Stehfest, E., Van Aardenne, J., Cooper, O. R., Kainuma, M., Mahowald, N., McConnell, J. R., Naik, V., Riahi, K., and van Vuuren, D. P.: Historical (1850-2000) gridded anthropogenic and biomass burning emissions of reactive gases and aerosols: methodology and application, Atmos. Chem. Phys., 10, 7017-7039, doi:10.5194/acp10-7017-2010, 2010.

Langmann, B., Duncan, B., Textor, C., Trentmann, J., and Vanderwerf, G.: Vegetation fire emissions and their impact on air pollution and climate, Atmos. Environ., 43, 107-116, doi:10.1016/j.atmosenv.2008.09.047, 2009.

Lathem, T. L., Beyersdorf, A. J., Thornhill, K. L., Winstead, E. L., Cubison, M. J., Hecobian, A., Jimenez, J. L., Weber, R. J., Anderson, B. E., and Nenes, A.: Analysis of CCN activity of Arctic aerosol and Canadian biomass burning during summer 2008, Atmos. Chem. Phys., 13, 2735-2756, doi:10.5194/acp-13-27352013, 2013.

Longo, K. M., Freitas, S. R., Andreae, M. O., Setzer, A., Prins, E., and Artaxo, P.: The Coupled Aerosol and Tracer Transport model to the Brazilian developments on the Regional Atmospheric Modeling System (CATT-BRAMS) - Part 2: Model sen- 
sitivity to the biomass burning inventories, Atmos. Chem. Phys., 10, 5785-5795, doi:10.5194/acp-10-5785-2010, 2010.

Makkonen, R., Seland, Ø., Kirkevåg, A., Iversen, T., and Kristjánsson, J. E.: Evaluation of aerosol number concentrations in NorESM with improved nucleation parameterization, Atmos. Chem. Phys., 14, 5127-5152, doi:10.5194/acp-14-5127-2014, 2014.

McFiggans, G., Artaxo, P., Baltensperger, U., Coe, H., Facchini, M. C., Feingold, G., Fuzzi, S., Gysel, M., Laaksonen, A., Lohmann, U., Mentel, T. F., Murphy, D. M., O’Dowd, C. D., Snider, J. R., and Weingartner, E.: The effect of physical and chemical aerosol properties on warm cloud droplet activation, Atmos. Chem. Phys., 6, 2593-2649, doi:10.5194/acp-6-2593-2006, 2006.

Mircea, M., Facchini, M. C., Decesari, S., Cavalli, F., Emblico, L., Fuzzi, S., Vestin, A., Rissler, J., Swietlicki, E., Frank, G., Andreae, M. O., Maenhaut, W., Rudich, Y., and Artaxo, P.: Importance of the organic aerosol fraction for modeling aerosol hygroscopic growth and activation: a case study in the Amazon Basin, Atmos. Chem. Phys., 5, 3111-3126, doi:10.5194/acp-53111-2005, 2005.

Nenes, A., Ghan, S., Abdul-Razzak, H., Chuang, P. Y., and Seinfeld, J. H.: Kinetic limitations on cloud droplet formation and impact on cloud albedo, Tellus B, 53, 133-149, doi:10.1034/j.16000889.2001.d01-12.x, 2001.

Padró, L. T., Moore, R. H., Zhang, X., Rastogi, N., Weber, R. J., and Nenes, A.: Mixing state and compositional effects on CCN activity and droplet growth kinetics of size-resolved $\mathrm{CCN}$ in an urban environment, Atmos. Chem. Phys., 12, 10239-10255, doi:10.5194/acp-12-10239-2012, 2012.

Petters, M. D. and Kreidenweis, S. M.: A single parameter representation of hygroscopic growth and cloud condensation nucleus activity, Atmos. Chem. Phys., 7, 1961-1971, doi:10.5194/acp-71961-2007, 2007.

Petters, M. D., Carrico, C. M., Kreidenweis, S. M., Prenni, A. J., DeMott, P. J., Collett, J. L., and Moosmüller, H.: Cloud condensation nucleation activity of biomass burning aerosol, J. Geophys. Res., 114, D22205, doi:10.1029/2009JD012353, 2009.

Phinney, L. A., Lohmann, U., and Leaitch, W. R.: Limitations of using an equilibrium approximation in an aerosol activation parameterization, J. Geophys. Res., 108, 4371, doi:10.1029/2002JD002391, 2003.

Pierce, J. R., Croft, B., Kodros, J. K., D’Andrea, S. D., and Martin, R. V.: The importance of interstitial particle scavenging by cloud droplets in shaping the remote aerosol size distribution and global aerosol-climate effects, Atmos. Chem. Phys., 15, 61476158, doi:10.5194/acp-15-6147-2015, 2015.

Pringle, K. J., Tost, H., Pozzer, A., Pöschl, U., and Lelieveld, J.: Global distribution of the effective aerosol hygroscopicity parameter for $\mathrm{CCN}$ activation, Atmos. Chem. Phys., 10, 52415255, doi:10.5194/acp-10-5241-2010, 2010.

Pruppacher, H. R. and Klett, J. D.: Microphysics of clouds and precipitation, Kluwer Academic Publishers, Cambridge, Massachussets, 2nd Edn., available at: http://www.tandfonline.com/ doi/abs/10.1080/02786829808965531, 1997.

Raatikainen, T., Moore, R. H., Lathem, T. L., and Nenes, A.: A coupled observation - modeling approach for studying activation kinetics from measurements of CCN activity, Atmos. Chem. Phys., 12, 4227-4243, doi:10.5194/acp-12-4227-2012, 2012.
Ramanathan, V.: Aerosols, Climate, and the Hydrological Cycle, Science, 294, 2119-2124, doi:10.1126/science.1064034, 2001.

Reid, J. S., Hobbs, P. V., Ferek, R. J., Blake, D. R., Martins, J. V., Dunlap, M. R., and Liousse, C.: Physical, chemical, and optical properties of regional hazes dominated by smoke in Brazil, J. Geophys. Res, 103, 32059-32080, 1998.

Reutter, P., Su, H., Trentmann, J., Simmel, M., Rose, D., Gunthe, S. S., Wernli, H., Andreae, M. O., and Pöschl, U.: Aerosol- and updraft-limited regimes of cloud droplet formation: influence of particle number, size and hygroscopicity on the activation of cloud condensation nuclei (CCN), Atmos. Chem. Phys., 9, 70677080, doi:10.5194/acp-9-7067-2009, 2009.

Rissler, J., Swietlicki, E., Zhou, J., Roberts, G., Andreae, M. O., Gatti, L. V., and Artaxo, P.: Physical properties of the submicrometer aerosol over the Amazon rain forest during the wetto-dry season transition - comparison of modeled and measured CCN concentrations, Atmos. Chem. Phys., 4, 2119-2143, doi:10.5194/acp-4-2119-2004, 2004.

Rissler, J., Vestin, A., Swietlicki, E., Fisch, G., Zhou, J., Artaxo, P., and Andreae, M. O.: Size distribution and hygroscopic properties of aerosol particles from dry-season biomass burning in Amazonia, Atmos. Chem. Phys., 6, 471-491, doi:10.5194/acp6-471-2006, 2006.

Rissman, T. A., Nenes, A., and Seinfeld, J. H.: Chemical amplification (or dampening) of the Twomey effect: Conditions derived from droplet activation theory, J. Atmos. Sci., 61, 919-930, 2004

Roberts, G. C., Nenes, A., Seinfeld, J. H., and Andreae, M. O.: Impact of biomass burning on cloud properties in the Amazon Basin, J. Geophys. Res., 108, 4062, doi:10.1029/2001JD000985, 2003.

Rosário, N. E., Longo, K. M., Freitas, S. R., Yamasoe, M. A., and Fonseca, R. M.: Modeling the South American regional smoke plume: aerosol optical depth variability and surface shortwave flux perturbation, Atmos. Chem. Phys., 13, 2923-2938, doi:10.5194/acp-13-2923-2013, 2013.

Rose, D., Nowak, A., Achtert, P., Wiedensohler, A., Hu, M., Shao, M., Zhang, Y., Andreae, M. O., and Pöschl, U.: Cloud condensation nuclei in polluted air and biomass burning smoke near the mega-city Guangzhou, China - Part 1: Size-resolved measurements and implications for the modeling of aerosol particle hygroscopicity and CCN activity, Atmos. Chem. Phys., 10, 33653383, doi:10.5194/acp-10-3365-2010, 2010.

Ruehl, C. R., Chuang, P. Y., and Nenes, A.: How quickly do cloud droplets form on atmospheric particles?, Atmos. Chem. Phys., 8, 1043-1055, doi:10.5194/acp-8-1043-2008, 2008.

Seinfeld, J. H. and Pandis, S. N.: Atmospheric Chemistry and Physics: From Air Pollution to Climate Change, 2nd Edn., Wiley Interscience, New Jersey, 2006.

Swietlicki, E., Hansson, H.-C., Hämeri, K., Svenningsson, B., Massling, A., Mcfiggans, G., Mcmurry, P. H., Petäjä, T., Tunved, P., Gysel, M., Topping, D., Weingartner, E., Baltensperger, U., Rissler, J., Wiedensohler, A., and Kulmala, M.: Hygroscopic properties of submicrometer atmospheric aerosol particles measured with H-TDMA instruments in various environments - a review, Tellus B, 60, 432-469, doi:10.1111/j.16000889.2008.00350.x, 2008.

Tosca, M. G., Randerson, J. T., and Zender, C. S.: Global impact of smoke aerosols from landscape fires on climate and 
the Hadley circulation, Atmos. Chem. Phys., 13, 5227-5241, doi:10.5194/acp-13-5227-2013, 2013.

van der Werf, G. R., Randerson, J. T., Giglio, L., Collatz, G. J., Mu, M., Kasibhatla, P. S., Morton, D. C., DeFries, R. S., Jin, Y., and van Leeuwen, T. T.: Global fire emissions and the contribution of deforestation, savanna, forest, agricultural, and peat fires (19972009), Atmos. Chem. Phys., 10, 11707-11735, doi:10.5194/acp10-11707-2010, 2010.

Vestin, A., Rissler, J., Swietlicki, E., Frank, G. P., and Andreae, M. O.: Cloud-nucleating properties of the Amazonian biomass burning aerosol: Cloud condensation nuclei measurements and modeling, J. Geophys. Res., 112, D14201, doi:10.1029/2006JD008104, 2007.

Ward, D. S., Eidhammer, T., Cotton, W. R., and Kreidenweis, S. M.: The role of the particle size distribution in assessing aerosol composition effects on simulated droplet activation, Atmos. Chem. Phys., 10, 5435-5447, doi:10.5194/acp-10-5435-2010, 2010.
Wex, H., McFiggans, G., Henning, S., and Stratmann, F.: Influence of the external mixing state of atmospheric aerosol on derived CCN number concentrations, Geophys. Res. Lett., 37, L10805, doi:10.1029/2010GL043337, 2010.

Wolfram Research, I.: Mathematica, Version 10.0, available at: http: //www.wolfram.com/mathematica/, 2014.

Wu, L., Su, H., and Jiang, J. H.: Regional simulations of deep convection and biomass burning over South America: 1. Model evaluations using multiple satellite data sets, J. Geophys. Res., 116, D17208, doi:10.1029/2011JD016105, 2011. 